
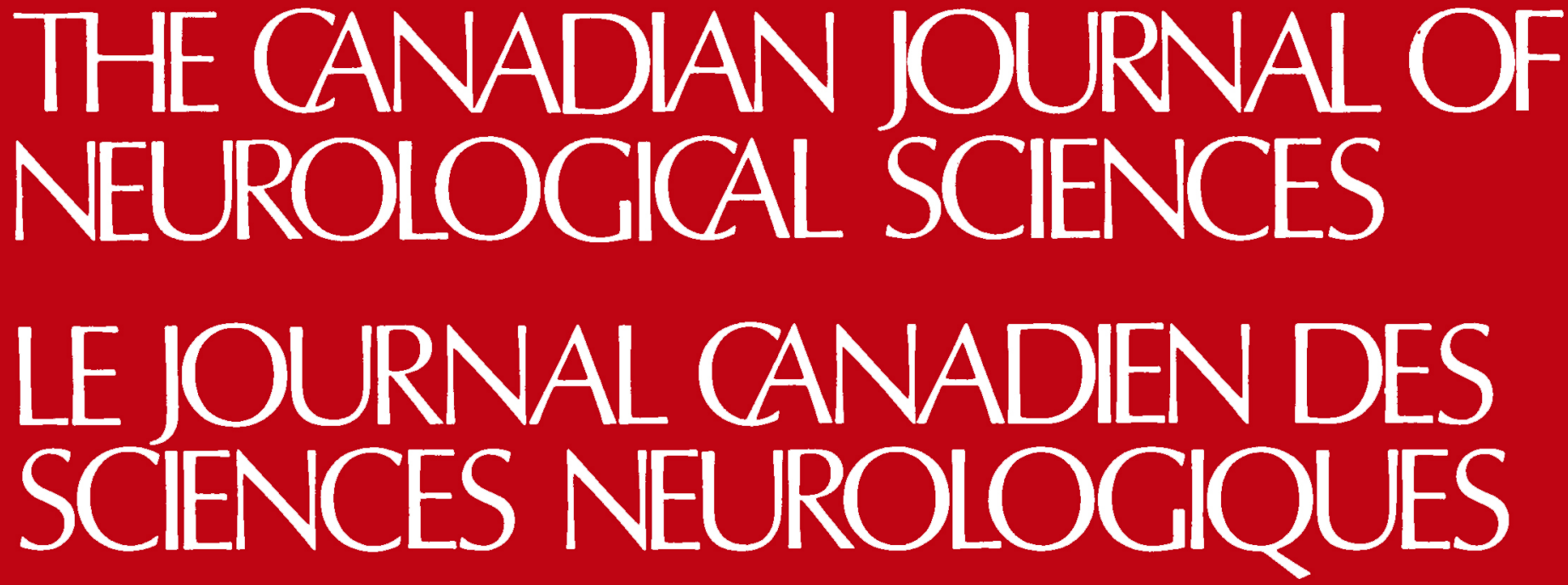

SUBJECT REVIEW: The Somatosensory Evoked Potential

A. Eisen

The Effects of Intermittent Insulin Therapy on the

Autonomic Neuropathy in the Streptozotocin Rat

Neonatal Myasthenia Gravis in the Infant of an

Asymptomatic Thymectomized Mother ..C.W. Olanow, R.J.M. Lane, K.L. Hull \& A.D. Roses

Transient Choreiform Dyskinesias During

Alcohol Withdrawal

OUEBEC COOPERATIVE STUDY OF FRIEDREICH'S ATAXIA.

Phase Three: Clinical Pathophysiology

Part Two: Enzymology and Experimental Trials

(detailed Table of Contents on Page 93)

XVII CANADIAN CONGRESS OF NEUROLOGICAL SCIENCES:

Program and Abstracts

Notes and Announcements

Book Reviews

\title{
Official Journal of
}

The Canadian Neurological Society

The Canadian Neurosurgical Sociely

The Canadian Society of Clinical Neurophysiologists

The Canadian Association tor Child Neurology

XVII Canadian Congress of Neurological Sciences

Toronto, Ontario

June $23-26,1982$ 


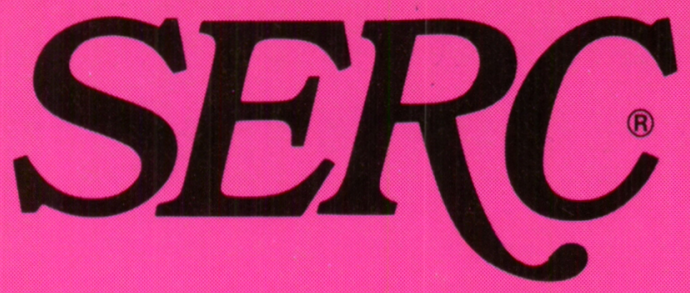

\section{For the management of Vertigo}

\section{- Proven efficacy}

"(Serc) is now a proven, useful therapeutic agent in the treatment of Ménière's disease, especially in the control of vertigo."

\section{- Restores vestibular responses}

"In a preliminary trial (Wilmot 1971) using objective testing of both auditory and vestibular function,...the results showed statistical significance in favour of Serc."2

\section{- Reduced severity of episodic vertigo}

"....a significant improvement in favour of the drug (Serc) with regard to vertigo, tinnitus and deafness. Vertigo was the most responsive symptom."

\section{Well tolerated}

"No adverse reactions were observed.""

\section{REFERENCES:}

1Frew. I.J.C. et al: Postgrad. Med. J. 52:501-503, 1976

2Wimot, T.J. et al: J. Laryng 0tol: 9:833-840, 1976.

PRESCRIBING INFORMATION INDICATIONS: SERC may be of value in reducing the episodes of vertigo in Meniere's disease. No claim is made for the effectiveness of SERC in the symptomatic treatment of any form of vertigo other than that associated with Meniere's disease.

DOSAGE AND ADMINISTRATION: The usual adult dosage has been one to two tablets (4 mg. each) administered orally three times a day.

Recommended starting dose is two tablets three times daily. Therapy is then adjusted as needed to maintain patient response. The dosage has ranged from two tablets per day to eight tablets per day. No more than eight tablets are recommended to be taken in any one

SERC (betahistine hydrochloride) is not recommended for use in children. As with all drugs, SERC should be kept out of reach of children.

CONTRAINDICATIONS: Several patients with a history of peptic ulcer have experienced an exacerbation of symptoms while using SERC. Although no causua relation has been established SERC is contraindicated in the presence of peptic ulcer and in patients with history of this condition. SERC is also contraindicated in patients with pheochromocytoma.

PRECAUTIONS: Although clinical intolerance to SERC by patients with bronchial asthma has not been demonstrated, caution should be exercised if the drug is used in these patients.

USE IN PREGNANCY: The safety of SERC in pregnancy has not been established. Therefore, its use in pregnancy or lactation, or in women of childbearing age requires that its potential benefits be weighed against the possible risks

ADVERSE REACTIONS: Occasional patients have experienced gastric upset, nausea and headache.

HOW SUPPLIED: Scored tablets of $4 \mathrm{mg}$ each in bottles of 100 tablets

Full prescribing information available on request.

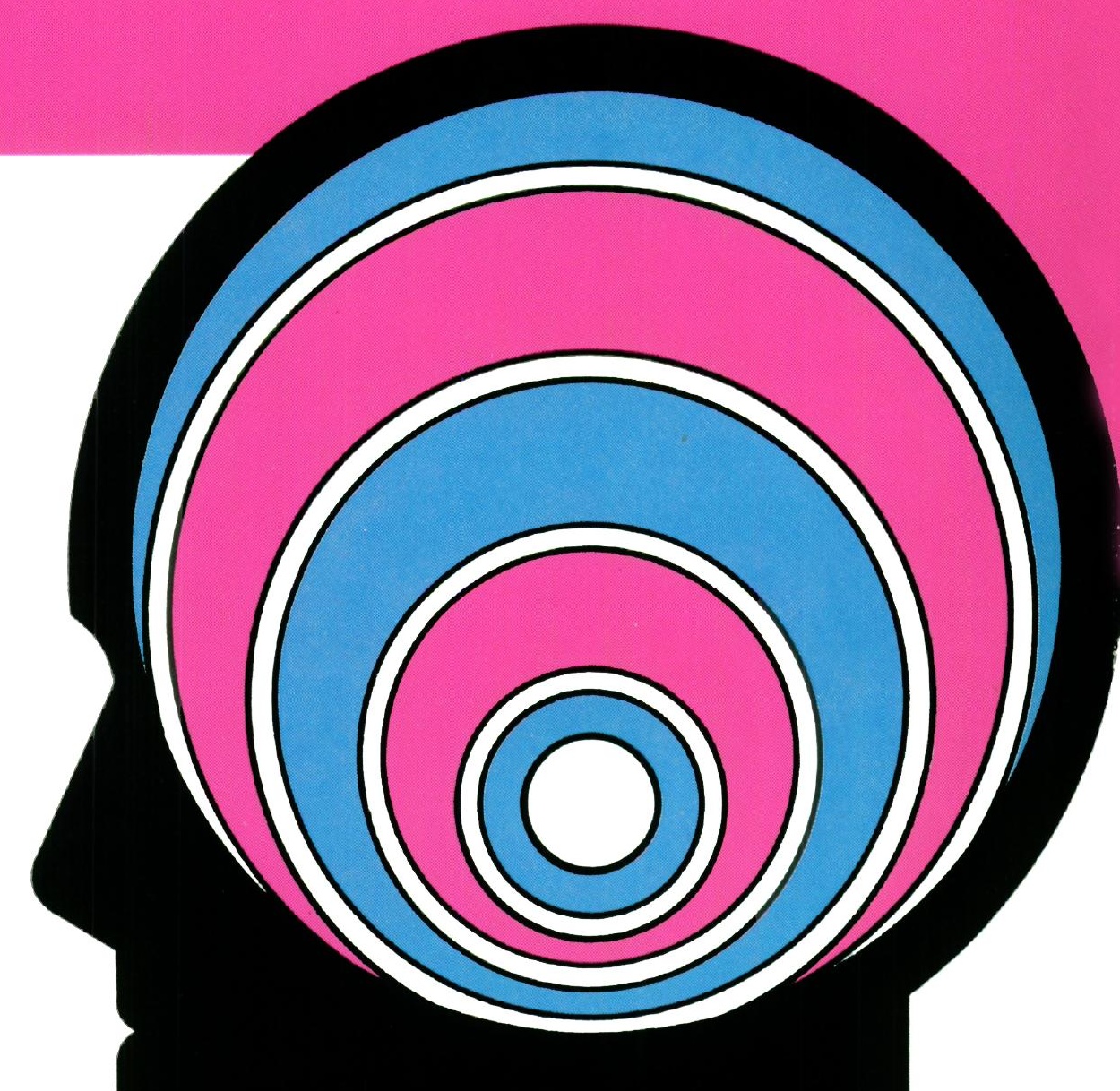

.




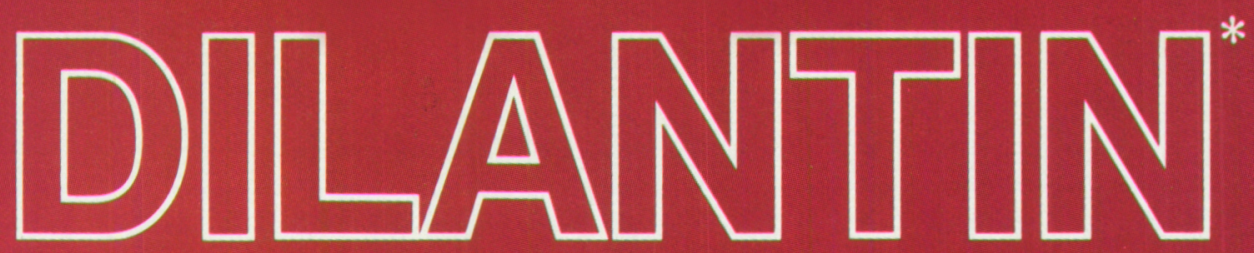

\section{Extended Phenytoin Sodium Capsules U.S.P. A RECOGNIZED DIFFERENCE}

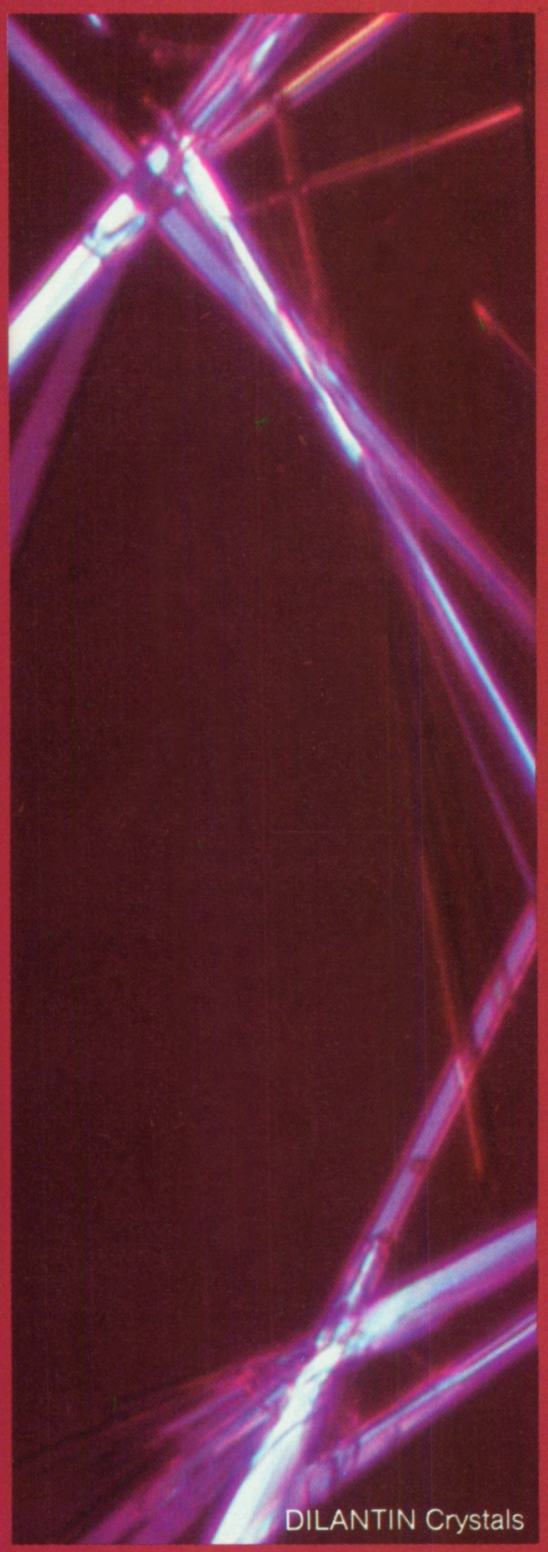

\section{USP XX now differentiates between Extended and Prompt Phenytoin Sodium Capsules.}

Extended phenytoin sodium has been recognized as a distinct pharmaceutical entity. Its slow dissolution and absorption do not create significant fluctuations in phenytoin blood levels.
Prompt phenytoin sodium has a faster dissolution and higher initial blood levels. The two forms of phenytoin sodium are not interchangeable.**

\section{DILANTIN Capsules have not changed.}

Extended effect has always been the action of DILANTIN therapy. Only the U.S.P. standards

have changed to recognize the difference between "extended" and "prompt" phenytoin sodium. Both you and your patient can continue to benefit from the consistent antiepileptic action of DILANTIN capsules.

\section{Once-daily-dosage option is confirmed for DILANTIN Capsules.}

Extended action of DILANTIN offers greater convenience and improved patient compliance. Dependable, effective therapy is now available through a oncedaily-dosage option, once seizure control has been established with divided doses.

\section{DILANTIN formulation ensures dependable bioavailability.}

Extended phenytoin classification of DILANTIN capsules is the result of its unique dissolution profile. Due to its special formulation, DILANTIN exerts a slow, steady release of phenytoin for dependable bioavailability.

**Patients should be maintained on one form of phenytoin (extended or prompt) to avoid toxicity or loss of seizure control.

\section{START WITH DILANTIN-STAY WITH DILANTIN FOR OVER A GENERATION,} THE STANDARD IN EPILEPSY MANAGEMENT 


\section{The Roche}

spectrum of anticonvulsants

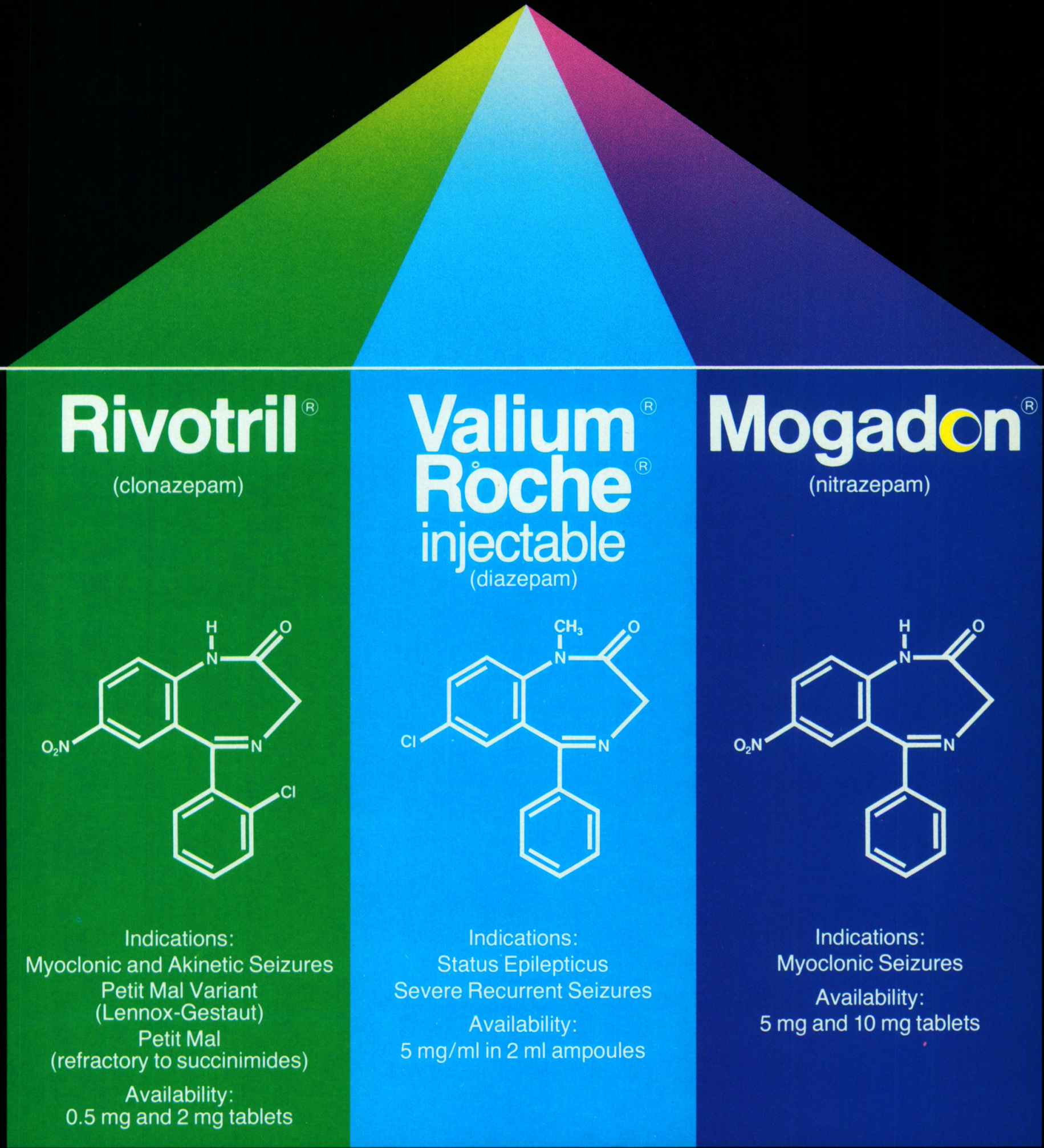




\section{4-CHANNEL EVOKED RESPONSE AND EMG-SYSTEM D1}

Incorporates a complete range of stimulators

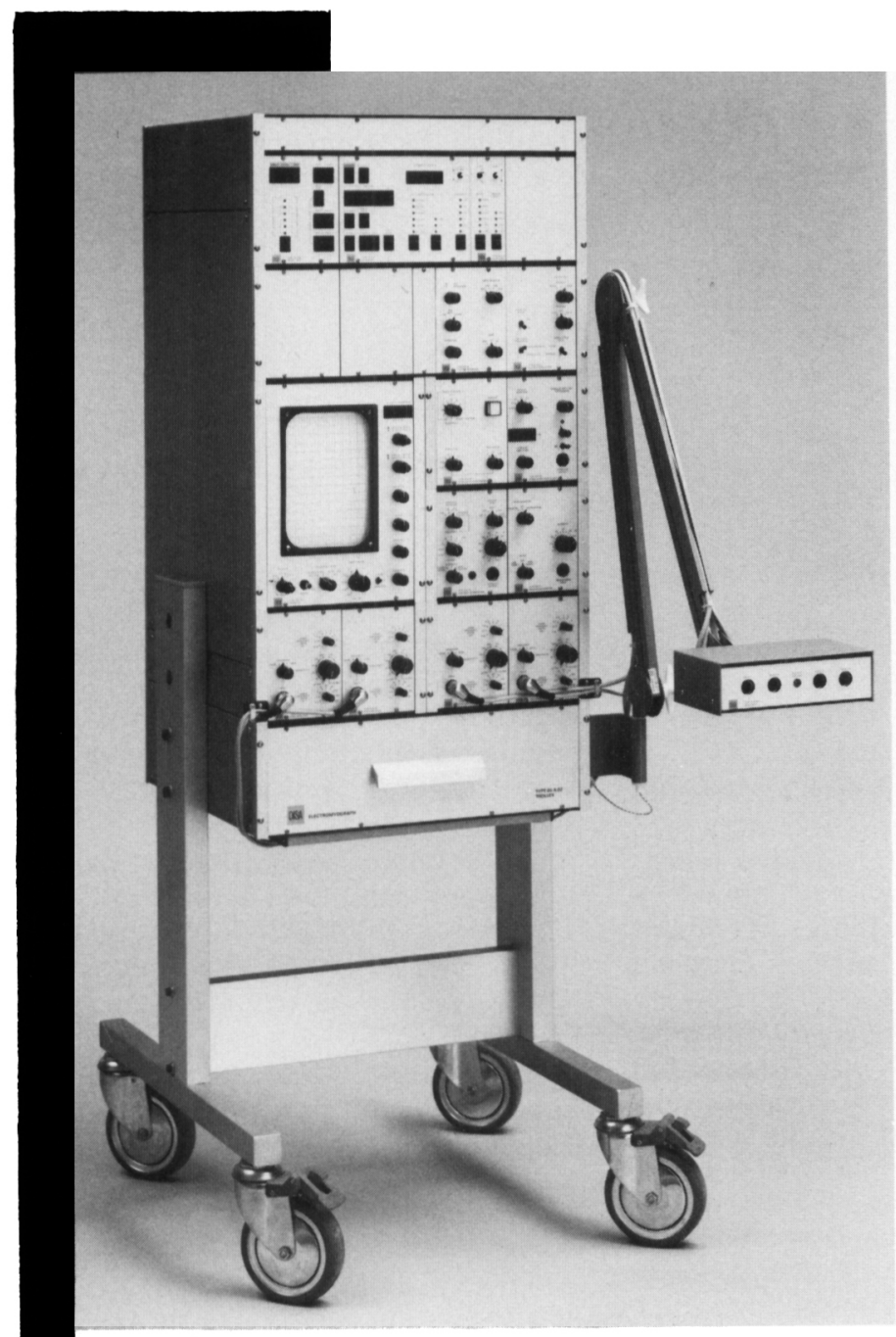

\section{Features}

* Records visual auditory and somato-sensory evoked potentials

* Amplifiers with extremely low noise level, high input impedance and extended frequency range

* 4-Trace Monitor with time expansion and digital display of latency and inter-peak intervals

* Storage function individually selectable on all four traces

* Performs simultaneous averaging of up to four input signals

* Individually selectable analysis time for the four input signals

* Improves the signal-to-noise ratio by a factor of up to 90

* Automatic rejection facility for overloaded input signals

* Time-transferred plotter function with high signal resolution

There are 40 years of experience behind the one instrument that allows you total Evoked Potentials and Electromyographic diagnostic capabilities. By employing a modularized approach to EP/EMG we are able to offer our customers one equipment package with the widest possible range of EP/EMG capabilities. The System D1 incorporates stimulator modules for Visual, Auditory and Somato-sensory Evoked Potentials that are recorded by means of an X-Y recorder incorporated in the drawer.

The DISA 1500 System adjusts to meet new requirements through the use of the appropriate "add-on" modules.

DISA has maintained its leading position in the EP/EMG field through the recent introduction of the above features.

For further information or a demonstration, please write to:

DISA Electronics Ltd.

140 Shorting Road

Scarborough, Ontario

M1S 3S6

416 298-2091
DISA Electronics

779 Susquehanna Avenue

in U.S.A. Franklin Lakes, N.J.

07417

$201891-9460$ 


\section{LE JOURNAL CANADIEN DES SCIENCES NEUROLOGIQUES}

\section{Editor}

Robert G. Lee

Calgary

\section{Editorial Board}

\section{Albert J. Aguayo}

Montreal

Henry J. M. Barnett

London

Paul Bédard

Quebec

Henry B. Dinsdale

Kingston

Guy Geoffroy

Montreal

Alan Hudson

Toronto

Yves Lamarre

Montreal

\section{News Editor}

Arthur J. Hudson

London

THE EDITORIAL BOARD wishes to publish original work in the basic and clinical neurosciences on the understanding that it has not been and will not be published elsewhere Review articles on timely subjects will be accepted. Manuscripts must be in triplicate including illustrations. One of the copies must be the original, ribbon copy. Manuscripts should be typed double spaced, on white paper.

Papers will be accepted in French or English. All papers should be accompanied by a short résumé in both languages. The résumé translation will be done by the editorial board if requested.

Papers should be identified only by the full name of the author, or authors, and the name of the place in which the work was done.

ILLUSTRATIONS: Photographs should be unmounted on glossy paper and show magnification scale. They should be marked on the back with figure number, title of paper and name of author.

Diagrams should be in India ink and large enough to be informative after reduction.

All illustrations should be referred to as figures, numbered consecutively, not included in the body of the text and all

\author{
Associate Editor \\ André Barbeau \\ Montreal
}

Bernard Lemieux

Sherbrooke

William J. Logan

Toronto

Morton Low

Vancouver

Thomas P. Morley

Toronto

Thomas J. Murray

Halifax

Donald Paty

Vancouver

Sidney J. Peerless

London

captions should be typed on a separate piece of paper.

Colored illustrations cannot usually be accepted unless the author is prepared to assist with the cost of reproduction.

REFERENCES to authors outside the context of the sentence should read (Name, Year). i.e. "However, a recent study (Bird and Iverson, 1975) showed a decreased, etc." Authors mentioned within the context of the sentence should read Name (Year), "i.e....twenty years since Ecker and Reimenshender (1951) demonstrated, etc." References should be typed in alphabetical order on a separate sheet and include author's name, initials, year, title, publication, volume first and last page, i.e. Isacson, P. (1967). Myx-oviruses and autoimmunity. Progress in Allergy, 10, 256-292. Abbreviations should be the same as those used in Cumulated Index Medicus.

Textbook references should include name of text, author's name, page number, publisher and city.

REPRINTS: Fifty reprints will be supplied free if ordered when the galley proofs are returned. More may be ordered at a nominal charge. Corrections and changes in the galley proofs, apart from printer's errors may be charged to the author.

This journal is indexed by Index Medicus, Excerpta Medica and Current
Founding Editor

Robert T. Ross

Winnipeg

Terry Picton
Ottawa

Jean Reiher

Sherbrooke

Leo P. Renaud

Montreal

Barry Rewcastle

Calgary

Matthew W. Spence

Halifax

William G. Tatton

Toronto

Bryce Weir

Edmonton

\section{Editorial Assistant}

Lucile G. Edwards

Calgary

\section{Contents - Clinical Practice and Life Science.}

SUBSCRIPTIONS: This journal is issued four times a year. The annual rate is $\$ 28.00$ for Canada and the U.S.A. $\$ 30.00$ elsewhere. Internes, Residents, Pre-and Post-Doctoral Students, $\$ 14.00$ per annum. Single copies $\$ 10.00$ each.

ADVERTISING: Enquiries regarding advertising space and rates should be directed to LEX LTD. VANCO PUBLICATIONS, 190 Main Street, Unionville, Ontario L3R 2G9. Telephone - (416) 297-2030.

All communications, manuscripts, subscriptions, etc., should be sent to the Editor, Canadian Journal of Neurological Sciences, Faculty of Medicine, 2500 University Drive, Calgary, Alberta, Canada T2N 1 N4.

COPYRIGHT ब1982 by THE CANADIAN JOURNAL OF NEUROLOGICAL SCIENCES INC. No part of this journal may be reproduced in any form without the prior permission of The Canadian Journal of Neurological Sciences.

Printed by Lawson Graphics Ltd., 708 Moray Street

Winnipeg, Manitoba R3J 359.

Mailed under second class registration number 3307. Postage paid at Winnipeg, Manitoba 
The Canadian Journal of Neurological Sciences is the official publication of the participating societies of the Canadian Congress of Neurological Sciences.

PUbliCATIONS COMMITTEE

Donald Baxter

Montreal

Andrew Eisen

Vancouver
Charles Tator

Toronto

\section{CANADIAN NEUROLOGICAL SOCIETY}

President

Past President

Vice-President

Secretary-Treasurer
Henry B. Dinsdale

Robert G. Lee

Thomas J. Murray

Robert F. Nelson

Department of Medicine

Ottawa General Hospital

Ottawa, Ontario K 1G 8L6
Council:

Michel Aubé

Michel Drolet

John Humphrey

Andrew Kertesz

Donald McLean

Peter Seland

\section{CANADIAN NEUROSURGICAL SOCIETY}

President

Past President

President Elect

Secretary-Treasurer
Jules Hardy

Peter Allen

Stuart Huestis

Gary Ferguson

University Hospital

London, Ontario N6A 5A5
Council:

Derek Fewer

Alain Godon

Robin Humphreys

Fala Maroun

Terry Myles

André Olivier

\section{CANADIAN SOCIETY OF CLINICAL NEUROPHYSIOLOGISTS \\ President \\ Past President \\ Secretary-Treasurer \\ Andrew Eisen \\ Jean Reiher \\ Warren Blume \\ University Hospital \\ London, Ontario N6A 5A5 \\ Council: \\ Roger Broughton \\ Reda El-Sawy \\ Normand Giard \\ Leroy Heffernan \\ Sherrill Purves}

\section{CANADIAN ASSOCIATION FOR CHILD NEUROLOGY}

President

Past President

Vice-President

Secretary-Treasurer
Rosalind Curtis

Warren Blume

Fred Andermann

Jean Gibson

I.W. Killam Hospital

P.O. Box 3070

Halifax, Nova Scotia B3J 3G9
Council:

Peter Camfield

Shashikant Seshia

Simon Verrett 


\section{THE CANADIAN JOURNAL OF NEUROLOGICAL SCIENCES}

VOL. 9, NO. 2 MAY 1982

SUBJECT REVIEW: The Somatosensory Evoked Potential - A. Eisen

The Effects of Intermittent Insulin Therapy on the Autonomic Neuropathy in The Streptozotocin Rat

G. Monckton \& E. Pehowich

Neonatal Myasthenia Gravis in the Infant of an Asymptomatic Thymectomized Mother

C.W. Olanow, R.J.M. Lane, K.L. Hull \& A.D. Roses

Transient Choreiform Dyskinesias During Alcohol Withdrawal

L. Fornazzari \& P.L. Carlen

QUEBEC COOPERATIVE STUDY OF FRIEDREICH'S ATAXIA.

Phase Three: Clinical Pathophysiology

Part Two: Enzymology and Experimental Trials

XVII CANADIAN CONGRESS OF NEUROLOGICAL SCIENCES:

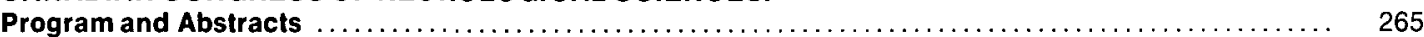

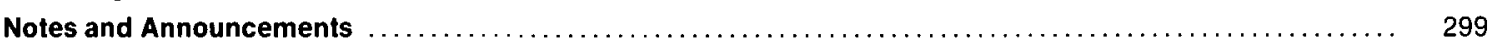

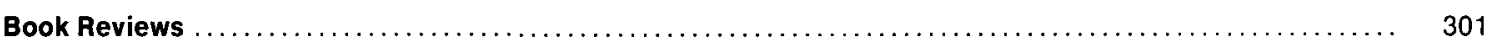


Briel Prescribing Intormation

Tegreto $200 \mathrm{mg}$ carbamazepine

Indications and Clinical Use

A. Trigeminal Neuralgia:

Tegretol is indicated for the symptomatic relief of pain of trigeminal neuralgia only during periods of exacerba reux). It should not be used preventively during periods reux). It should not be used preventively during periods glossopharyngeal neuralgia. For patients who fail to respond to Tegretol, or who are sensitive to the drug recourse to other accepted measures must be considered.

Tegretol is not a simple analgesic and should not be

used to relieve trivial facial pain

1) in the management of psychomotor (temporal lobe) epilepsy and,

2) as an adjunct, in some patients with secondary or partial epilepsy with complex symplomatology or secondarily generalized seizures, when administered in

3) as an alternative medication in patients with generatc) as an alternative medication in patients with generatside effects or fail to respond to other anticonvulsant trugs.

Tegretol is essentially ineffective in controlling petit mal, minor motor, myoclonic and predominantly unilateral seizures, and does not prevent the generalization of epileptic discharge.

Tegretol should not be administered to patients with a history of hepatic disease or serious blood disorder. Tretol should not be administered immediately before, in conjunction with, or immediately after a monoamine oxidase inhibitor. When it seems desirable to Minter Tegretol to a patient who has been receiving MAO inhibitor, there should be as long a drug-free should this the clincal condion allows, but in no case Tegretol should be low initially, and increased very grad ually

Tegretol should not be administered to patients present ing atrioventricular heart block.

Safe use in pregnancy has not been established. There fore. Tegretol should not be administered during the given to women of childbearing potential unless, in the given to women of childbearing potential unless, in the patient outweigh the possible risk to the foetus (See city in nursing animals. Tegretol should not be administered to nursing mothers.

Because of the similarity of chemical structure.

Tegretol should not be administered to patients with

known hypersensitivity to any of the tricyclic com-

pounds, such as amitriptyline, trimipramine, imipramine,

or their analogues or metabolites.

Warnings

Although reported infrequently, serious adverse effects have been observed during the use of Tegretol. Agranilocytosis and aplastic anemia have occurred in a lew cytopenla and hepatocellular and cholestatic jaundice have also been reported. It is, therefore, important that Tegretol should be used carefully and close clinical and trequent laboratory supervision should be maintained throughout treatment in order to detect as early as possible signs and symptoms of a possible blood dyscrasia.

Long-lerm toxicity studies in rats indicated a potential carcinogenic risk. Therefore, the possible risk of drug use musi be welghed against the potential benefits before prescribing carbamazepine to individual patients.

Monitoring of Haematological and Other Adverse ReacMonitoring of Haematological and Other Adverse
tions: Complete blood studies, including platelet tions: Complete blood studies, including platelet and urinalysis should be carried out before treatment is should be maintained throughout treatment, including trequent performance of complete blood counts in order to detect any early signs or symptoms of blood dyscrasia. Should any signs or symptoms or abnormal laboratory findings suggestive of blood dyscrasia or liver disorder occur. Tegretol should be immediately discontinued until the case is carefully reassessed.

Urinary Retention and increased intraocular Pressure Because of its anticholinergic action. Tegretol should be given cautiously, if at ali, to patients with increased intraocular pressure or urinary retention. Such patients should be followed closely while taking the drug. Occurrence of Behavioural Disorders: Because it is closely related to the other tricyclic drugs, there is some possibility that Tegretol might activate a latent osychosis, or, in elderly patients, produce agitation or confusion, especially when combined with other drugs. Caution should also be exercised in alcoholics. Use in Patients with Cardiovascular Disorders: Tegretol should be used cautiously in patients with a history of coronary artery disease, organic heart disease, or congestive failure. If a defective conductive system is suspected, an E.K.G. should be performed before admin tering Tegretol, in order to exclude patients with atrioventricular block. Use in Patients taking Oral Contraceptives: In women under treatment with Tegretol, the reliability of oral con traceptives may be adversely affected; such patients should accordingly be advised to use some alternative. non-hormonal method of contraception

Oriving and operating Hazardous Machinery: Because dizziness and drowsiness are possible side effects of Tegretol, patients shoud be warned about the possible hazards of operating machinery or driving automobiles. Adverse Reactlons

The reactions which have been most frequently Thorted win the feet, vertigo, dizziness, gastrointestinal disturb- during the initial phase of therapy. They have rarely necessitated discontinuing Tegretol therapy, and can be minimized by initiating treatment at a low dosage. The more serious adverse reactions observed are the haematologic, hepatic, cardiovascular and dermatologic reactions, which require discontinuation of therapy.

The following adverse reactions have been reported Haematological reactions: Transitory leucopenia, eosinophilia, leucocytosis, thrombocytopenic purpura. agranulocytosis, macrocytic anemia and aplastic anemia. In a few instances, deaths have occurred. Hepatic disturbances: During the long-term administraand cholestatic or hepatocellular jaundice have been observed.

Dermatological reactions: The following reactions occurred during treatment with Tegretol: skin sensitivity reactions and rashes, erythematous rashes, pruritic eruptions, urticaria, photosensitivity, pigmentary changes, neurodermatitis and in rare cases StevensJohnson syndrome, exfoliative dermatitis, alopecia, diaphoresis, erythema multiforme, erythema nodosum, and aggravation of disseminated lupus erythematosus. occurring during treatment with Tegretol include verfusion, headache, fatigue, blurred vision, transient diplopia adache, fat gue, blurred vision, transient ances, abnormal involuntary movements and increase in motor seizures. In addition, peripheral neuritis and in motor seizures. In addition, peripheral neuritis and nystagmus, and tinnitus have been reported but only very rarely. There have been some reports of paralysis very rarely. There have been some reports of paralysis but no conclusive relationship to the administration of Tegretol could be established.

Cardiovascular systems: Recurrence of thrombophlebitis in patients with a prior history of thrombophlebitis, congestive heart failure aggravation of hypertension. Stokes-Adams in patients with AV block, hypotension, syncope and collapse, edema, aggravation of coronary syncope and collapse, edema, aggravation of coronary myocardial infarction and arrhythmia) have been associated with other tricyclic compounds.

Genitourinary reactions: Urinary frequency, acute urinary retention, oliguria with elevated blood pressure. and impotence. Elevation of BUN, alb

Digestive tract: Disturbances associated with Tegretol therapy have included nausea. vomiting, gastric or abdominal discomfort diarrhoea, anorexia and dryness of the mouth and throat, glossitis and stomatitis. Eyes: There is no conclusive evidence that Tegretol produces pathological changes in the cornea, lens or retina. However, it should be recognized that many phenothiazines and related drugs have been shown to cause eye changes. By analogy, periodic eye examinations, including slitla

recommended.

Other reactions reported during treatment with Tegretol include fever and chills, lymphadenopathy, aching joints and muscles, leg cramps and conunctivitis.

Dosage and Administration

Use in Epilepsy (see Indications): A low initial daily dosage with a gradual increase in dosage is advised.
Dosage should be adjusted to the needs of the individ ual patient.

Adults and Children over 12 years of age: Initially, 100 to $200 \mathrm{mg}$ once or twice a day depending on the sever initial dosage is progressively increased, until the best initial dosage is progressively increased, until the best response is obtained, up to $600 \mathrm{mg}$ daily. The usua dosages up to 800 to $1000 \mathrm{mg}$ have been used for short periods. As soon as disappearance of seizures has periods. As soon as disappearance of seizures has reduced very gradually until a minimum effective cose reached.

Use in-trigeminal neuraigia: The initial daily dosage should be small; $200 \mathrm{mg}$, taken in two doses of $100 \mathrm{~m}$ increased by $200 \mathrm{mg}$ per day until relief of pain is obtained. This is usually achieved at a dosage between 200 and $800 \mathrm{mg}$ daily, but occasionally up to $1200 \mathrm{mg}$ per day may be necessary. As soon as relief of pain has per day may be necessary. As soon as relief of pain has dosage should be attempted until a minimum effective dosage should be attempted until a minimum effect
dosage is reached. Because trigeminal neuralgia is characterized by periods of remission, attempts should be made to reduce or discontinue the use of Tegretol at intervals of not more than 3 months, depending upon the individual clinical course.

Prophylactic use of the drug in trigeminal neuralgia is not recommeded.

Tegretol should be taken in two or three divided doses daily, with meals whenever possible.

Dosage Forms

Tegretol is available as a $200 \mathrm{mg}$ white, round, flat, bevelled-edged, double-scored tablet, imprinted with the GEIGY monogram.

Availability

Bottles of 50 and 500 tablets. Protect from heat and humidity.

Full information available on reques

See outside back cover.

\begin{tabular}{|l|}
\hline PAAB \\
CCPP
\end{tabular}

Geigy
Dorval, Qué. H9S 181 G-9091

Prolopa Roche

\section{Ax Summary}

Indications

drug induced parkinsonism.

Contraindications

ersensitivity to levodopa and/or benserazide. In patients in whom sympathornimetic amines are contraindicated; in conjunction with monoamine oxidase inhibitors or within two weeks of their withdrawal. Clinical or laboratory evidence of uncompensated cardiovascular, endocrine renal, hepatic, hematologic or pulmonary disease: narrowprovided intraocular pressure remains under control).

Warnings

Discontinue levodopa therapy at least 12 hours before initiarecommendations.

Increase dosage of 'Prolopa' $100-25$ gradually to avoid inducing CNS side effects (abnormal movements). Observe patients for signs of depression with suicidal tendencies with history of psychotic disorders or those receiving reserpine, phenothiazines or tricyclic antidepressants. Administer with care to patients with history of myocardial infarction or who have atrial, nodal or ventricular arrhythmias. Safety in patients under 18 years has not been established. In women who are or may become pregnant benefits should be weighed against possible hazards to mother

and fetus. Should not be given to nursing mothers. Administer with caution to patients with history of melanoma or suspicious undiagnosed skin lesions.

Precautions

Caution in patients with history of convulsive disorders. Upper gastrointestinal hemorrhage possible in patients

Normal activity should be resumed gradually to avoid risk of injury.

medication with caution to patients on antihypertensive medication. $P r C$

Monitor intraocular pressure in patients with chronic wideangle glaucoma.

\section{Adverse Reactions}

Most common are abnormal involuntary movements. usually dose dependent, which may disappear or become tolerable after dosage reduction.

Most serious after prolonged therapy are periodic oscillations in performance (end of dose akinesia, on-off phenomenon and akinesia paradoxica)

Nausea, vomiting, arrhythmias and orthostatic hypotension occur less frequently than with levodopa alone.

anxiety agitation, ageres, including nild elaion, depression, anxiety, agitation, aggression, hallucinations and delusions

consult monograph for complete list of reported adverse effects.

Dosage

mmended initial dose is one capsule 'Prolopa' 100-25 once or twice daily, increased carefully by one capsule every third or fourth day until an optimum therapeutic dosage, increments should be made slowly at 2 to 4 wee

Optimal dosage for most patients is 4 to 8 capsules of 'Prolopa' 100-25 daily (400-800 mg levodopa) divided into 4 to 6 doses. Most patients require no more than 6 capsules 'Prolopa 100-25 ( $600 \mathrm{mg}$ levodopa) per day 'Prolopa is required to minimize adverse effects.

'Prolopa' 200-50 capsules are intended only tor maintenance therapy once the optimal dosage has been determined using 'Prolopa' $100-25$ capsules. No patients should receive $1200 \mathrm{mg}$ levodopa) during the first year of treatment. For patients previously treated with levodopa, discontinu
this medication for 12 hours and initiate treatment with 'Prolopa' $100-25$ or 'Prolopa' 50-12.5 so as to provide approximately $15 \%$ of the previous levodopa dosage. The initial daily dose, however, should not exceed 6 capsules 'Prolopa' 100-25 divided into 4 to 6 doses.

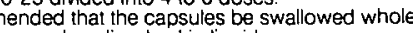



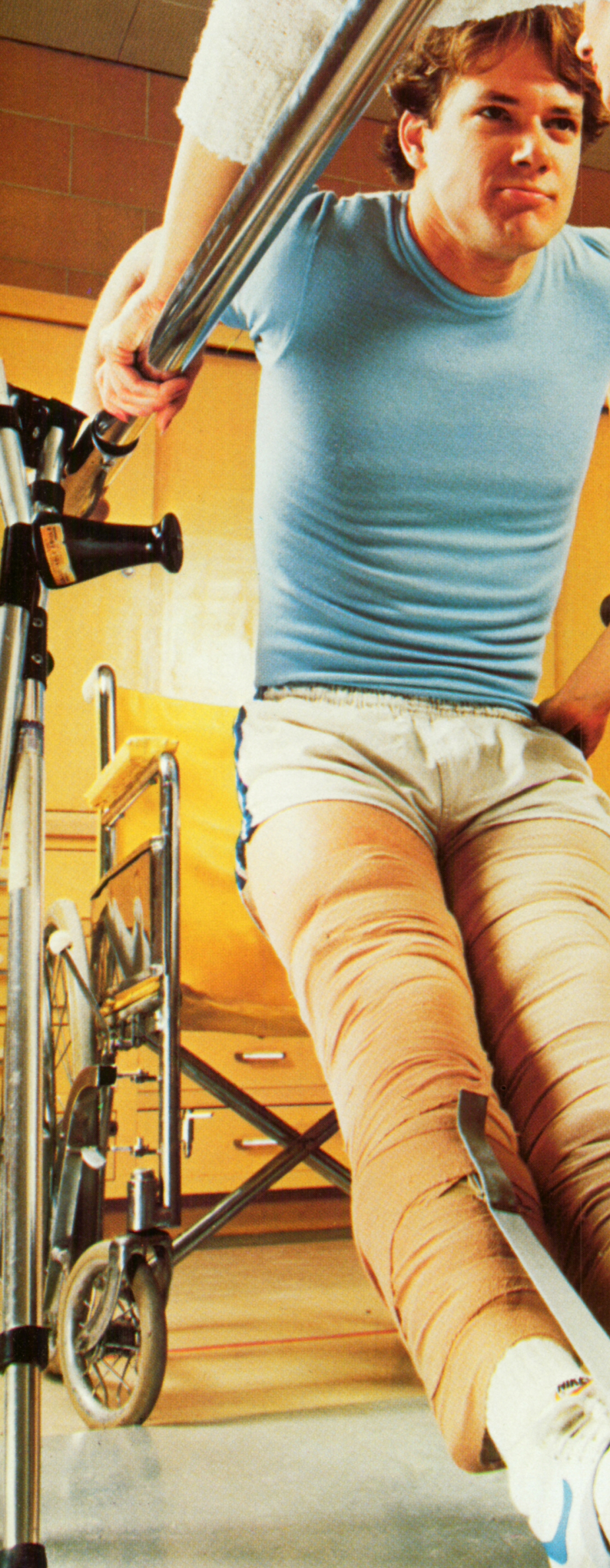
Brief Prescribing Information

RLioresal ${ }^{\oplus}$ baclofen

Action

The precise mechanisms of action of Lioresal (baclofen) are not fully known. It inhibits both monosynaptic and polysynaptic reflexes at the spinal level, probably by hyperpolarization of afferent terminals, although actions at supraspinal sites may also occur and contribute to its clinical effect. Although Lioresal is an analog of the putative inhibitory neurotransmitter gamma-amindbutyric acid (GABA), there is no conclusive evidence that actions on GABA systems are involved in the production of its clinical effects. Peak plasma concentrations of Lioresal are achieved within 2 hours and the plasma half-life is 2.4 hours. Indications and Clinical Uses

Lioresal (baclofen) is useful for the alleviation of signs and symptoms of spasticity resulting from multiple sclerosis.

Lioresal may also be of some value in patients with spinal cord injuries and other spinal cord diseases.

\section{Contraindications}

Hypersensitivity to Lioresal (baclofen).

Warnings

Abrupt Drug Withdrawal: Following abrupt withdrawal of Lioresal (baclofen), visual and auditory hallucinations, confusion, anxiety with tachycardia and sweating, insomnia, and worsening of spasticity have occurred.

Therefore, except for serious adverse

reactions, the dose should be reduced slowly when the drug is discontinued. Impaired Rena Function: Because Lioresal is primarily excreted unchanged through the kidneys, it should be given with caution, and it may be necessary to reduce the dosage. Stroke: Lioresal has not significantly benefited patients with stroke. These patients have also shown poor tolerability to the drug. Pregnancy: Safe use of Lioresal during pregnancy or lactation has not been established. High doses are associated with an increased incidence of abdominal hernias in the fetuses of rats and of ossification defects in those of rats and

rabbits. Therefore, the drug should be administered to pregnant patients, or women of child. bearing potential only when, in the judgment

of the physician, the potential benefits

outweigh the possible hazards.

\section{Precautions}

Safe use of Lioresal (baclofen) in children under age 12 has not been established and it is, therefore, not recommended for use in children. Because of the possibility of sedation, patients should be cautioned regarding the operation of automobiles or dangerous machinery, and activities made hazardous by decreased alertness. Patients should also be cautioned that the central nervous system effects of Lioresal may be additive to those of alcohol and other CNS depressants. Lioresal should be used with caution where spasticity is utilized to sustain upright posture and balance in locomotion, or whenever spasticity is utilized to obtain increased function. Extreme caution should be exercised in patients with epilepsy or a history of convulsive disorders. In such patients, the clinical state and electroencephalogram

should be monitored at regular intervals during therapy, as deterioration in seizure control and EEG has been reported occasionally in patients taking Lioresal. Caution should be used in treating patients with peptic

ulceration, severe psychiatric disorders, elderly patients with cerebrovascular disorders, and in patients receiving antihypertensive therapy. It is not known whether Lioresal is excreted in human milk. As a general rule, nursing should not be undertaken while a patient is on a drug since many drugs are excreted in human milk. Adverse Reactions

The most common adverse reactions associated with Lioresal (baclofen) are transient drowsiness, dizziness, weakness and fatigue. Others reported: Neuropsychiatric Headache $(<10 \%)$, insomnia $(<10 \%)$, and rarely, euphoria, excitement, depression, confusion, hallucinations, paresthesia, muscle pain, tinnitus, slurred speech, coordination disorder, tremor, rigidity, dystonia, ataxia, blurred vision, nystagmus, strabismus, miosis, mydriasis, diplopia, dysarthria, epileptic seizures. Cardiovascular: Hypotension $(<10 \%)$ rare instances of dyspnea, palpitation, chest pain, syncope. Gastrointestinal: Nausea (approx. 10\%), constipation $(<10 \%)$, and, rarely, dry mouth, anorexia, taste disorder abdominal pain, vomiting, diarrhea, and positive test for occult blood in stool.
Genitourinary: Urinary frequency $(<10 \%)$, and, rarely, enuresis, urinary retention, dysuria, impotence, inability to ejaculate, nocturia, hematuria. Other: Instances of rash, pruritus, ankle edema, excessive perspiration, weight gain, nasal congestion. Some of the CNS and genitourinary symptoms reported may be related to the underlying disease rather than to drug therapy.

The following laboratory tests have been found to be abnormal in a few patients receiving Lioresal: SGOT, alkaline phosphatase and blood sugar (all elevated).

Symptoms and Treatment of Overdosage Signs and Symptoms: Vomiting, muscular hypotonia, hypotension, drowsiness, accommodation disorders, coma, respiratory depression, and seizures. The signs and symptoms may be further aggravated by co administration of a variety of other agents including alcohol, diazepam, and tricyclic antidepressants. Treatment: The treatment is symptomatic. In the alert patient, empty the stomach promptly by induced emesis followed by lavage In the obtunded patient, secure the airway with a cuffed endotracheal tube before beginning lavage (do not induce emesis). Maintain adequate respiratory exchange; do not use respiratory stimulants. Muscular hypotonia may involve the respiratory muscles and require assisted respiration. $A$ high urinary output should be maintained since Lioresal

(baclofen) is excreted mainly by the kidneys.

Dialysis is indicated in severe poisoning associated with renal failure.

Dosage and Administration

The determination of optimal dosage of

Lioresal (baclofen) requires individual titration.

Start therapy at a low dosage and increase

gradually until optimum effect is achieved

(usually between $40-80 \mathrm{mg}$ daily)

The following dosage titration schedule is suggested:

$5 \mathrm{mg}$ t.i.d. for 3 days

$10 \mathrm{mg}$ t.i.d. for 3 days

$15 \mathrm{mg}$ t.i.d. for 3 days

$20 \mathrm{mg}$ t.i.d. for 3 days

Thereafter additional increases may be necessary but the total daily dose should not exceed a maximum of $80 \mathrm{mg}$ daily $(20 \mathrm{mg}$ q.i.d.). The lowest dose compatible with an optimal response is recommended. If benefits are not evident after a reasonable trial period, patients should be slowly withdrawn from the drug (see Warnings).

Availability: Lioresal (baclofen) $10 \mathrm{mg}$ tablets. Description: White to off-white flat-faced, oval tablets with Geigy monogram on one side and the identification code 23 below the monogram. Fully bisected on the reverse side. Available in bottles of 100 tablets.

\section{References:}

1.R.F. Jones, J.W. Lance, Medical Journal of Australia, 1976, May:654-657.

2.R.G. Feldman: Symposia Reporter, Vol. 3, No.2 June 1979.

3. Lioresal Product Monograph.

Product monoraph supplied on request.
MOVING?

PLEASE NOTIFY US OF YOUR CHANGE OF ADDRESS IN ADVANCE.

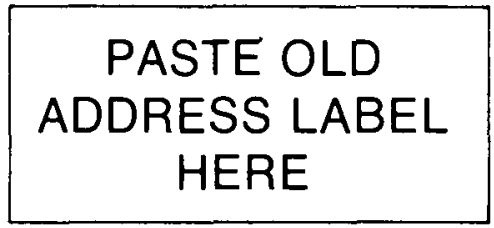

NEW ADDRESS:

NAME:

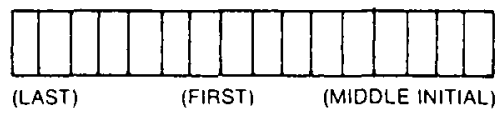

STREET ADDRESS:

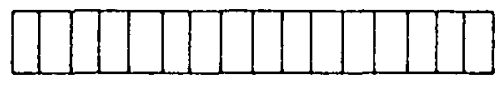

CITY:

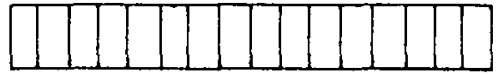

PROVINCE/STATE:

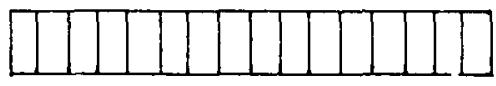

COUNTRY:

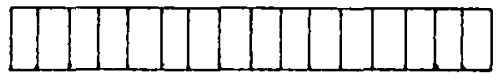

POSTAL/ZIP CODE:

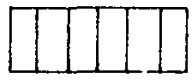
MAIL TO:
Editor
University of Calgary
Faculty of Medicine
Dept. of Clinical Neuro Sciences
Calgary, Alberta
T2N 4N1 


\section{The Advantages of ENTROPHEN*}

\section{To reduce the risk of strolse \\ Now, ENTROPHEN* is} indicated for reducing the risk of recurrent transient ischemic attacks or stroke in men who have had transient ischemia of the brain due to fibrin platelet emboli. At present there is no evidence that ASA is effective in reducing transient ischemic attacks in women, or is of benefit in the treatment of completed strokes in men or women.

Inhibition of platelet cyclooxygenase activity by a single dose of ENTROPHEN*-10 was comparable to that of plain ASA, although the effect was delayed, reflecting the delayed appearance of ASA in the plasma. ${ }^{1}$

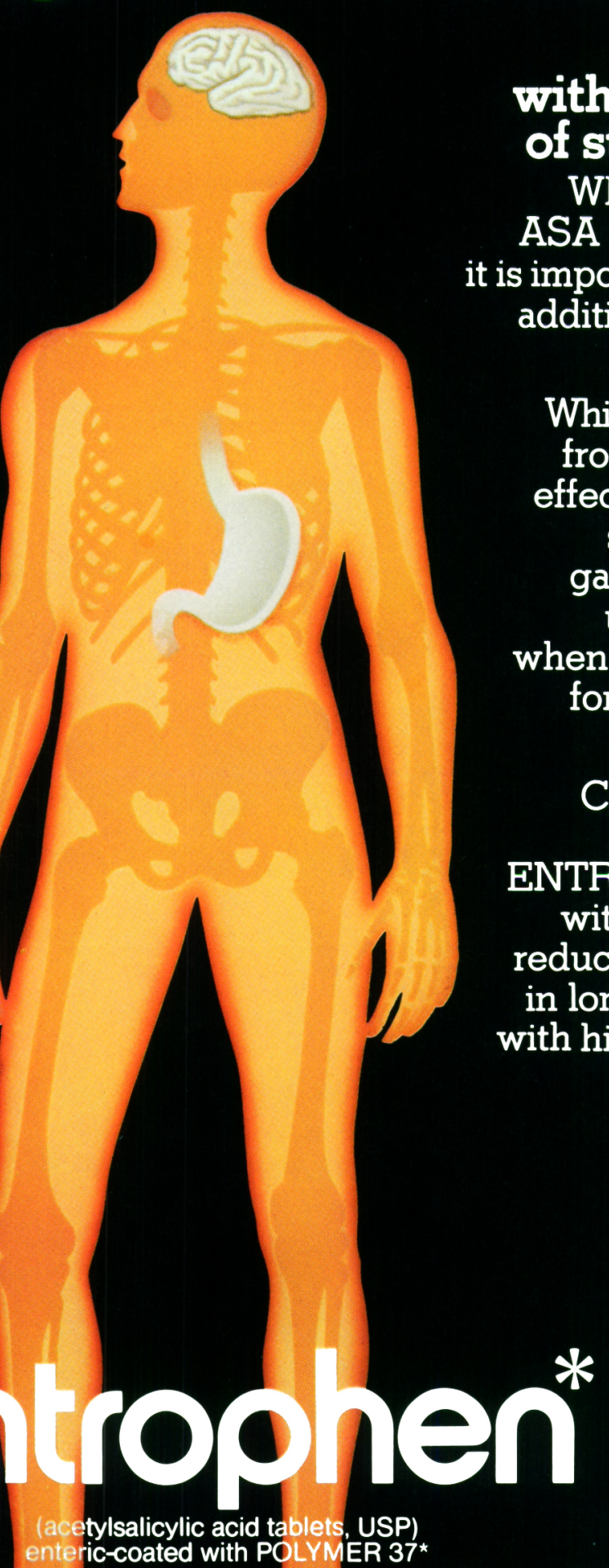

with reduced risk of stomach upset

When you prescribe SA for long-term use, mportant not to create problems for your patients.

While they may benefit from the therapeutic effect of ASA, there is still a potential for gastric irritation and upset, particularly or continuous daily dosage.

Clinical experience has shown that OPHEN ${ }^{\star}$, coated with POLYMER 37* reduces gastric distress in long-term treatment high doses of ASA. the risk of stroke with reduced risk of stomach upset 


\section{entrophen*}

(acetylsalicylic acid tablets, USP)

Enteric-coated with POLYMER 37*

Anti-inflammatory-Analgesic Agent

DESCRIPTION

Platelet Aggregation Inhibitor

ENTROPHEN* is an enteric-coated tablet contain ing acetylsalicylic acid coated with POLYMER $37^{*}$ a partially esterified polyvinyl alcohol.

\section{ACTION}

Acetylsalicylic acid (ASA) has analgesic, antipyretic and anti-inflammatory properties.

In rheumatic diseases, although the analgesic and antipyretic effects are useful, the major ourpose for which ASA is used is to reduce the intensity of the inflammatory process. Inhibition of prostaglandin synthesis may be involved in the antiinflammatory action of ASA

ASA also alters platelet aggregation and release reaction by inhibiting prostaglandin synthesis Thromboxane $A_{2}$ is an essential step in piatele aggregation. ASA prevents Thromboxane $A_{2}$ formation by acetylation of platelet cyclooxygenase. This inhibition of prostaglandin synthesis is irreversible and affects platelet function for the life of the platelet.

The POLYMER $37^{*}$ coating substantially resists disintegration in aqueous fluids having a pH lower than 3.5 for a period of at least 2 hours and is capable of disintegrating in aqueous fluids having a pH of at least 5.5 in from 10 to 30 minutes. Thus, POLYMER $37^{*}$ coating effectively inhibits the release of ASA in the stomach, whilst allowing the tablet to dissolve in the upper portion of the small intestine for absorption from the duodenal area. Clinical experience has shown that POLYMER 37 coated acetylsalicylic acid diminishes or eliminate gastric distress during long-term treatment with high doses of ASA

\section{INDICATIONS}

ENTROPHEN* is indicated whenever gastric intolerance to ASA is of concern.

ENTROPHEN* is indicated for the relief of signs and symptoms of the following

Osteoarthritis

Rheumatoid arthritis

Spondylitis

Bursitis

and other forms of rheumatism

Musculoskeletal disorders

Rheumatic fever, however, penicillin and other appropriate therapy should be administered concomitantly.

ASA is generally considered to be the primary therapy for most forms of arthritis.

ENTROPHEN ${ }^{*}$ is aiso indicated for reducing the risk of recurrent transient ischemic attacks or stroke in men who have had transient ischemia of the brain due to fibrin platelet emboli. At present there is no evidence that ASA is effective in reducing transient ischemic attacks in women, or is of benefit in the treatment of completed strokes in men or women.

CONTRAINDICATIONS

Sensitivity to the ingredients

Active peptic ulce

Patients who had a bronchospastic reaction to ASA or non-steroidal anti-inflammatory drugs.

WARNINGS

ASA is one of the most frequent causes of accidental poisoning in toddlers and infants. ENTROPHEN" should, therefore, be kept well out of the reach of all children.

PRECAUTIONS

Salicylates should be administered with caution to patients with asthma and other allergic condtions. with a history of gastrointestinal ulcerations, with bleeding tendencies, with significant anemia or with hypoprothrombinemia.

Salicylates can produce changes in thyroid function tests.

Acute hepatitis has been reported rarely in patients with systemic lupus erythematosus and juvenile rheumatoid arthritis with plasma salicylate concentrations above $25 \mathrm{mg} / 100 \mathrm{~mL}$.
Patients have recovered upon cessation of therapy.

\section{Use in Pregnancy}

ASA does not appear to have any teratogenic effects. ASA has been found to delay parturition in rats. This effect has also been described with non-steroidal anti-inflammatory agents which inhibit prostaglandin synthesis.

High doses ( $3 \mathrm{~g}$ daily) of ASA during pregnancy may lengthen the gestation and parturition time Because of possible adverse effects on the Because of possible adverse effects on the blood loss, ASA should be avoided during the last three months of pregnancy.

Drug Interactions

Caution is necessary when ENTROPHEN and anticoagulants are prescribed concurrently, as ASA may potentiate the action of anticoagulants Salicylates may potentiate sulfonylurea hypoglycemic agents. Large doses of salicylates may have a hypolycemic action and thus. affect the insulin requirements of diabetics.

Although salicylates in large doses are uricosuric agents, smaller amounts may depress uric acid clearance and thus decrease the uricosuric effects of probenecid, sulfinpyrazone and phenylbutazone.

Sodium excretion produced by spironolactone may be decreased in the presence of salicylates. Salicylates also retard the renal elimination of methotrexate.

\section{ADVERSE REACTIONS}

Gastrointestinal reactions: nausea, vomiting. diarrhea, gastrointestinal bleeding and/or ulceration. Ear reactions: tinnitus, vertigo, hearing loss. Hematologic reactions: leukopenia, thrombocytopenia. Durpura. Dermatologic and Hypersensitivity reactions: urticaria, angioedema, pruritus. various skin eruptions. asthma and anaphylaxis. Miscellaneous reactions: acute reversible hepatotoxicity. mental confusion, drowsiness. sweating and thirst.

\section{SYMPTOMS AND TREATMENT}

\section{OF OVERDOSAGE}

\section{Symptoms}

in mild overdosage these may include rapid and deep breathing nausea, vomiting (leading to alkalosis). hyperpnea, vertigo, tinnitus, flushing. sweating thirst and tachycardia. (High blood levels of ASA lead to acidosis.) Severe cases may show fever hemorrhage excitement confusion. convulsions or coma, and respiratory failure.

Treatment

Treatment is essentially symptomatic and supportive. Administer water, universal antidote and remove by gastric lavage or emesis. Force fluids e e.g., sally broth) to replar sodium lass. If the patient is unable to retain flu sorally, the alkalosis can be treated by hypertonic saline intravenously. If salicylism acidosis is present. sodium bicarbonate intravenously is preferred because it increases the renal excretion of salicylates. Vhemin $K$ is indicated if there is evidence of hemorrhage. Hemodialysis has been used with success.

Respiratory depression may require artificial ventilation with oxygen. Convulsions may best be treated by the administration of succinylcholine and artificial ventilation with oxygen. Central nervous system depressant agents should not be used.

Hyperthermia and denydration are immediate threats to life and initial therapy must be directed to their correction and to the maintenance of adequate renal function. External cooling with cool water or alcohol should be provided quickly cool water or alcohol should be provided quickly to any
$104^{\circ} \mathrm{F}$.

\section{DOSAGE AND ADMINISTAATION}

Analoesic; entipyretic

Up to $2.925 \mathrm{~g}$ daily as necessary.

Anti-inflammatory

Because the suppression of inflammation increases with the dose of salicylate even beyond the point of toxicity, the therapeutic objective is to employ as large a dose as possible short of to employ as large a dose as possible short of levels in the range of 20 to $25 \mathrm{mg}$ per cent. The levels in the range of 20 to $25 \mathrm{mg}$ per cent. The therapeutic response to ASA is the administration therapeutic response
The generally accepted way to achieve eftective anti-inflammatory salicylate blood levels of 20 to $25 \mathrm{mg}$ per cent is to titrate the dosage by starting with 2.6 to $3.9 \mathrm{~g}$ daily, according to the size, age and sex of the palient. If necescary the dosage is then sex of the patient. If necessary, the dosage is then gradually adjusted by daily increments of $0.65 \mathrm{~g}$ until symptoms of salicylism 0.9 ., auditory symptoms, occur. Then, the dosage is decreased by $0.65 \mathrm{~g}$ daily until these symptoms disappear and maintained at that lover as long as necessary. In adults the median dose at which tinnitus develops is $4.5 \mathrm{~g}$ per day, but the range extends from 2.6 to $6.0 \mathrm{~g}$ per day.

Intermittent administration is ineffective. Patients should be advised not to vary the dose from day to day depending on the level of pain because that that of of the inflammation. A continuous regimen of $0.65 \mathrm{~g}$ four times daily is considered to be should be administered four times daily. For nighttime and early morning benefits. the last dose time and early morning be

Once maintenance dose is established. ENTROPHEN*-15 may be useful to encourage patient compliance.

Optimally, salicylate therapy should be monitored by periodic blood salicylate level determinations. If this is nood salicylape level determinations. If this is not practical, the appearance of auditory symptoms in the form of tinnitus or deafness are acceptable as an indicatic

There is an inverse relation between blood salicylate levels at which auditory symptoms appear and the age of the patient. In the young adult, this is usually in the range of 20 to $30 \mathrm{mg}$ per cent. In children. however, the level may be much higher, or the effect apparently absent. Because salicylate toxicity may appear without such warning in children, the usual practice is to give ASA in a daily dose of 50 to $100 \mathrm{mg}$ per kilogram of body weight and to follow blood levels aiming for a concentration of about $30 \mathrm{mg}$ per cent. Rheumatic Fever

A total daily dosage of $100 \mathrm{mg}$ per kilogram of body weight administered in divided doses to allay the pain. swelling and fever.

Cerebral ischemic attacks (men)

The recommended dosage is $1,300 \mathrm{mg}$ per day (650 $\mathrm{mg}$ twice a day or $325 \mathrm{mg}$ four times a day). AVAILABILITY

No. 472-ENTROPHEN*-15 tablets containing $975 \mathrm{mg}$ of acetylsalicylic acid USP, coated with POLYMER $37^{\star}$. Oval, pale yellow, film-coated tablets with the FROSST name engraved on one face and $\mathbf{4 7 2}$ on the other and supplied in bottles of 100 and 500

No. 470-ENTROPHEN"-10 tablets containing $650 \mathrm{mg}$ of acetylsalicylic acid USP, coated with POLYMER 37*. Oval, orange, film-coated tablets. with the FROSST name engraved on one face and 470 on the other and supplied in bottles of 100,500 and 1.000 .

No. 438 -ENTROPHEN *-5 tablets containing $325 \mathrm{mg}$ of acetylsalicylic acid USP, coated with POLYMER $37^{*}$ Round, brown, film-coated tablets, with the FROSST name engraved on one face and 438 on the other and supplied in bottles of 100,500 and 1,000

FULL PRODUCT MONOGRAPH AVAILABLE ON REOUEST.

1-188

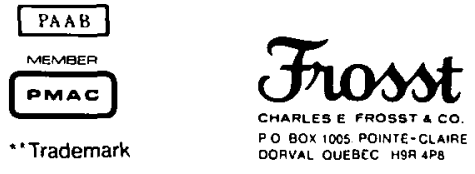




\section{INDEX TO ADVERTISEMENTS}

Abbott Laboratories, Depak ane - (xiv)

Frosst, Entrophen - (x) and (xi)

DISA - (iii)

Geigy, Tegretol - outside back cover, (vii)

Geigy, Lioresal - (viii) and (ix)

Grass Instruments,

Polysomnographic Recording (xvi)

Heerbrugg Microscopes - (xiii)

Hoffman-LaRoche, Rivotril (ii),

Prolopa - inside back cover and (vii)

Parke Davis, Dilantin, Zarontin - (i) and

(xii)

Unimed Canada, Serc - inside front cover
How doyou spell

truth in

advertising?

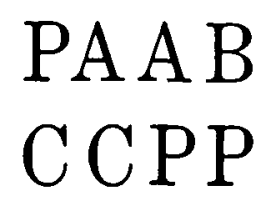

This logo appearing on pharmaceutical advertisements in professional journals means that the advertisements have man reviewod-and cleared for publishing - by the Phardo Publieite Pharmaceutique. Thls unique sereening system tor pharmaceutical edvertisDirectore is composed of individuals representing the following orgenizations: - Associstion des tabricents du Qubbec de Produits Pharmaceutiques. Association des modocina de langue francalse du Canads. Associstion of Codical Moda Cansdan Advertising Advisory Board

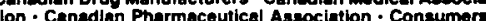
Aseocletion of Cenada. Phermaceutical Menufacturers Aseciation of Canada.

The Hoath Protection Branch of Hoathn and Woltare Canade acts as advisor and resource body to the board.

The program ensures the accuracy of pharmeceutical advertising to the health professions, so that it may continue to serve the ultimate best interest of the pationt.

\section{BRIEF PRESCRIBING INFORMATION}

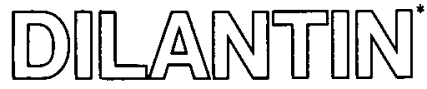

Extended Phenytoin

Sodium Capsules, U.S.P $100 \mathrm{mg}$

ANTICONVULSANT

\section{INDICATIONS}

Dilantin is indicated for the control of generalized tonic-clonic (grand mal) seizures and complex partial (psychomotor) seizures.

\section{CONTRAINDICATIONS}

Dilantin is contraindicated in those patients with a history of hypersensitivity to hydantoin products.

\section{WARNINGS}

Abrupt withdrawal of phenytoin in epileptic patients may precipitate status epilepticus. Phenytoin is not indicated in seizures due to hypoglycemia or other causes which may be immediately identified and corrected

Phenytoin metabolism may be significantly altered by the concomitant use of other drugs such as

A Barbiturates may enhance the rate of metabolism of phenytoin. This effect, however, is variable and unpredictable. It has been reported that in some patients the concomitant administration of carbamazepine resulted in an increased rate of phenytoin metabolism.

B Coumarin anticoagulants, disulfiram, phenylbutazone, and sulfaphenazole may in. hibit the metabolism of phenytoin, resulting in increased serum levels of the drug. This may lead to an increased incidence of nystagmus, ataxia, or other toxic signs.

C Isoniazid inhibits the metabolism of phenytoin so that with combined therapy, patients 'nn are slow acetylators may suffer from phenytoin intoxication.

D Tricyclic antidepressants in high doses may precipitate seizures, and the dosage of phenytoin may have to be adjusted accordingly.

Usage in Pregnancy: The effects of Dilantin in human pregnancy and nursing infants are unknown.

The prescribing physician will have to determine the risk/benefit in treating or coun selling epileptic women of childbearing potential.

\section{PRECAUTIONS}

The liver is the chief site of biotransformation of phenytoin, patients with impaired liver function may show early signs of toxicity. Elderly patients or those who are gravely ill may show early signs of toxicity.

A small percentage of individuals who have been treated with phenytoin have been shown to metabolize the drug slowly. Slow metabolism may be due to limited enzyme availability and lack of induction; it appears to be genetically determined.

Phenytoin has been associated with reversible lymph node hyperplasia. If lymph node enlargement occurs in patients on phenytoin, every effort should be made to substitute another anticonvulsant drug or drug combination.

Drugs that control generalized tonic-clonic (grand mal) seizures are not effective for absence (petit mal) seizures. Therefore, if both conditions are present, combined drug therapy is needed.

Hyperglycemia, resulting from the drug's inhibitory effect on insulin release, has been reported. Phenytoin may also raise the blood sugar level in persons already suffering from hyperglycemia.

\section{ADVERSE REACTIONS}

Central Nervous System: The most common manifestations encountered with phenytoin therapy include nystagmus, ataxia, slurred speech, and mental confusion. Dizziness, insomnia, transient nervousness, motor twitchings, and headache have also been observed. These side effects may disappear with continuing therapy at a reduced dosage level.

Gastrointestinal System: Phenytoin may cause nausea vomiting, and constioation. Administration of the drug with or immediately after meals may help prevent gastrointestinal discomfort.

Integumentary System: Dermatological manifestations sometimes accompanied by fever have included scarlatiniform or morbilliform rashes.

Hemopoietic System: Hemopoietic complications, some fatal, have occasionally been reported in association with administration of phenytoin. These have included thrombocytopenia, leukopenia, granulocytopenia, agranulocytosis, and pancytopenia.

Other: Gingival hyperplasia occurs frequently; this incidence may be reduced by good oral hygiene including gum massage, frequent brushing and appropriate dental care. Polyarthropathy and nirsutism occur occasionally. Hyperglycemia has been reported. Toxic hepatitis, liver damage, and periarteritis nodosa may occur and can be fatal.

\section{MANAGEMENT OF OVERDOSAGE}

The mean lethal dose in aduits is estimated to be 2 to 5 grams. The cardinal initial symptoms are hystagmus, ataxia and dysarthria. The patient then becomes coma. tose, the pupils are unresponsive and hypotension occurs. Death is due to respiratory depression and apnea. Treatment is nonspecific since there is no known antidote. First the stomach should be emptied. If the gag reflex is absent, the airway should be supported. Oxygen, vasopressors and assisted ventilation may be necessary for central nervous system, respiratory and cardiovascular depression. Finally, hemodialysis can be considered since phenytoin is not completely bound to plasma proteins. DOSAGE AND ADMINISTRATION

Dosage should be individualized to provide maximum benefit. In some cases, serum blood level determinations may be necessary for optimal dosage adjustments - the clinically effective serum level is usually $10-20 \mathrm{mcg} / \mathrm{mL}$

Adult Dose: Patients who have received no previous treatment may be started on one $100 \mathrm{mg}$ Dilantin Capsule three times daily, and the dose then adjusted to suit individual requirements.

Pediatric Dose: Initially, $5 \mathrm{mg} / \mathrm{kg} /$ day in two or three equally divided doses, with subsequent dosage individualized to a maximum of $300 \mathrm{mg}$ daily. A recommended daily maintenance dosage is usually 4 to $8 \mathrm{mg} / \mathrm{kg}$. Children over 6 years old may require the minimum adult dose ( $300 \mathrm{mg} /$ day). Pediatric dosage forms available include a $30 \mathrm{mg}$ Capsule, a $50 \mathrm{mg}$ palatably flavoured infatab. or an oral suspension form containing $30 \mathrm{mg}$ of Dilantin in each $5 \mathrm{~mL}$.

Alternative Dose: Once-a-day dosage for adults with $300 \mathrm{mg}$ of Dilantin may be considered if seizure control is established with divided doses of three $100 \mathrm{mg}$ Capsules daily.

HOW SUPPLIED

Dilantin $100 \mathrm{mg}$ Capsules; in bottles of $100 \& 1000$

Complete prescribing information available upon request.

\section{PARKE-DAVIS}

*Reg. T.M. Parke Davis \& Company

Parke-Davis Canada inc., auth. use 


\section{Mobile, stable and optically}

unicue: Surcical operating
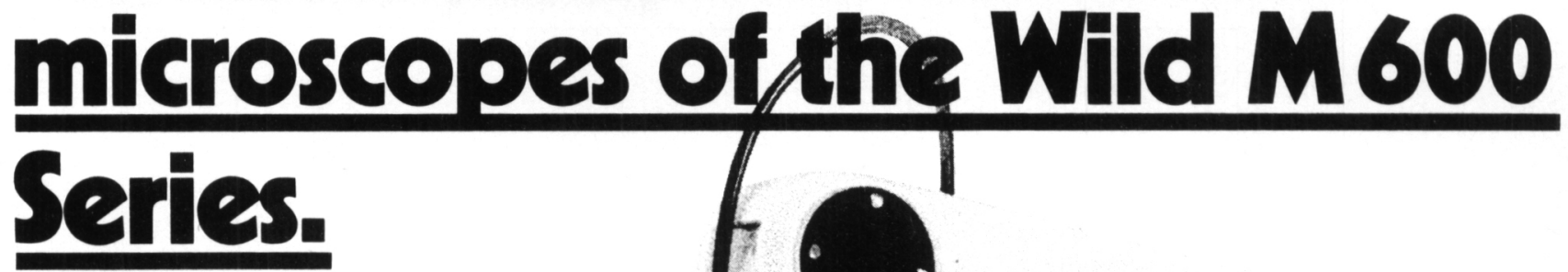

The brand-new concepts of the WILD Surgical Operating Microscopes offer decisive advantages for microsurgery.

- See more with the refined optical system

- Position comfortably with the articulated, balanced modular design

- Work confidently with the rugged, stable stand and the sterilisable controls

- Expand individually for photography, cine and TV without special modifications
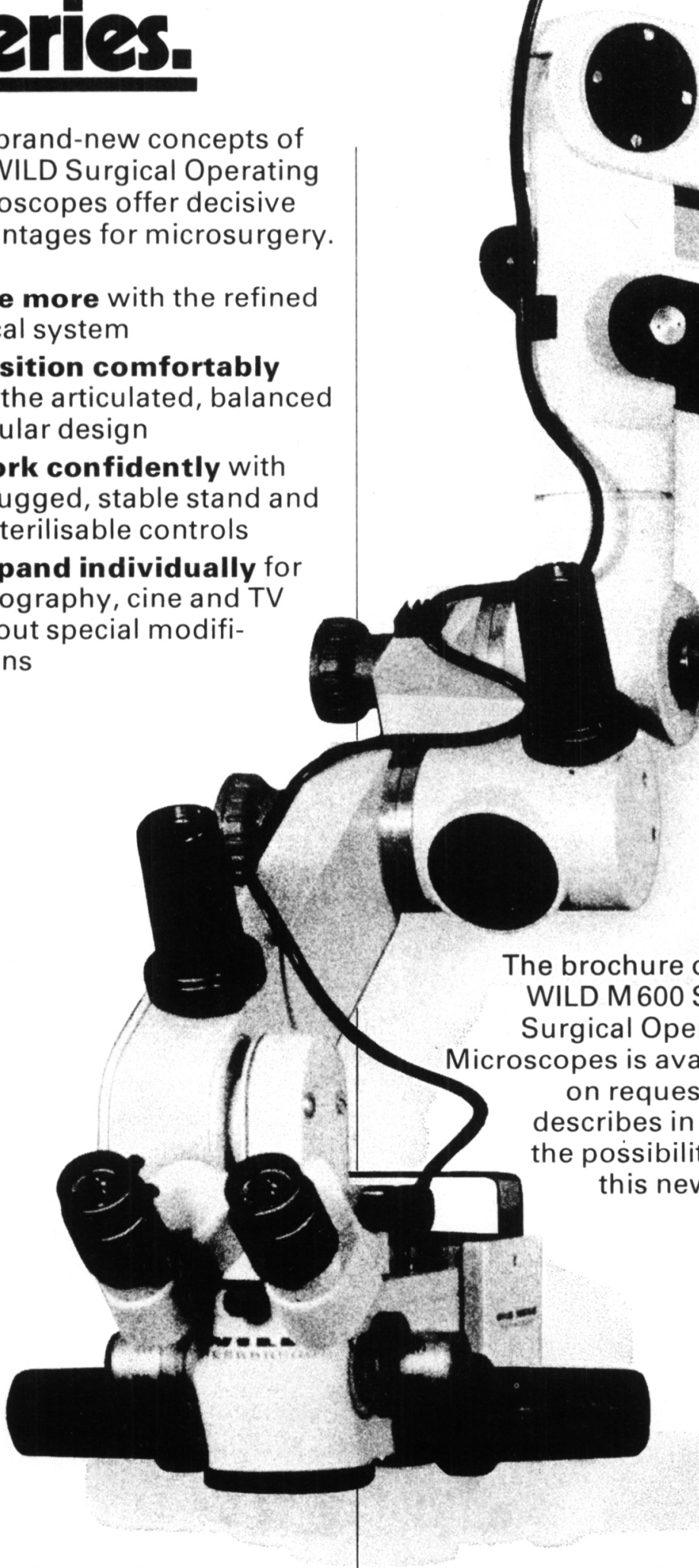


\section{you wouldn't guess
Jane's an epileptic}

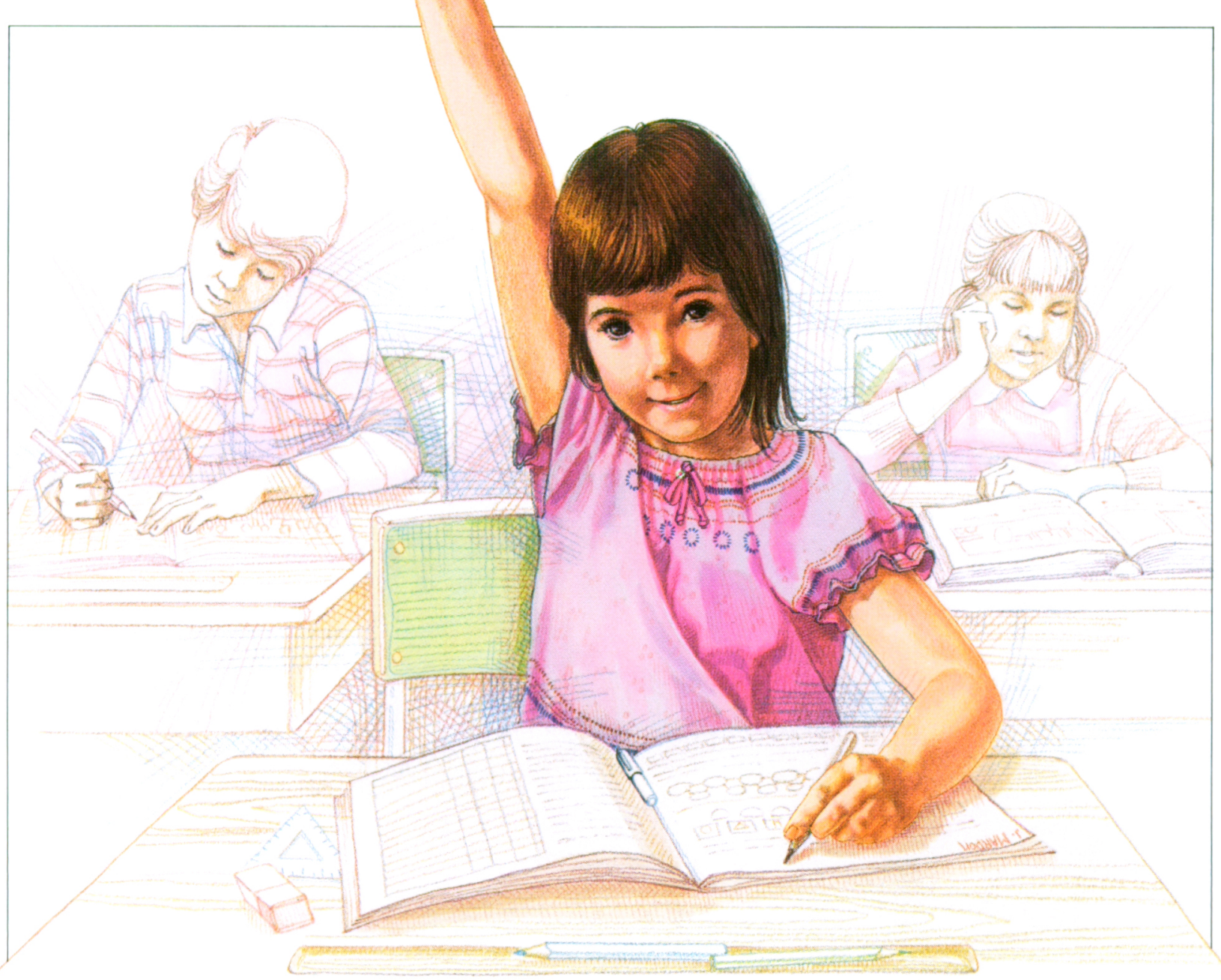

Epileptic therapy doesn't have to interfere with her life. Depakene can effectively control seizures, with little risk of disturbed behaviour or poor performance.

Depakene provides broad-spectrum seizure control Depakene is considered a drug of first choice for simple and complex absence seizures ${ }^{1,2}$ and has been successfully used in tonic-clonic or myoclonic seizures with absence components. 3,4

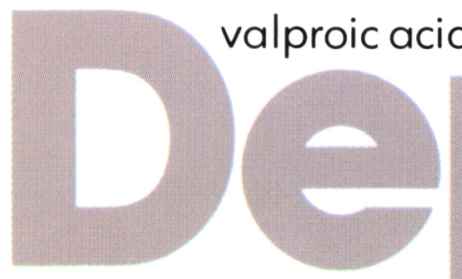

brings many
No impairment of learning Depakene has made patients more alert, more lively and better able to perform daily tasks. ${ }^{5}$

Positive effect on behaviour Depakene, unlike phenobarbital, rarely affects behaviour, and may actually improve it. ${ }^{5}$
Low incidence of disturbing side effects Depakene does not cause hirsutism, gum hyperplasia or acne, nor has it been associated with aplastic anemia or agranulocytopenia.

Minimizes problems of polypharmacy Depakene is often effective as single therapy. When other anticonvulsants are necessary, their dosage may be reduced.

New dosage convenience A 500-mg enteric-coated capsule is now available.
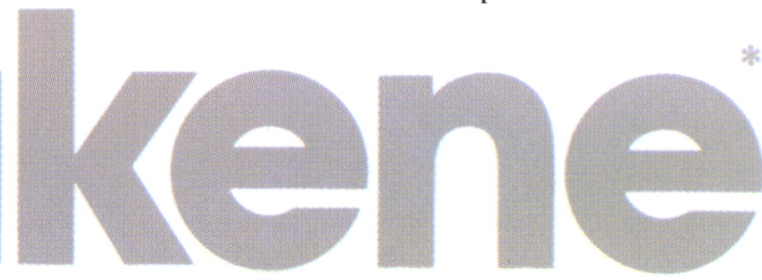

\section{epileptic patients closer to normal}




\section{Brief prescribing information}

INDICATIONS AND CLINICAL. USE: Depakene (valproic acid) is indicated for use as sole and adjunctive therapy in the treatment of simple and complex absence seizures, including petit mal. Valproic acid may also be used adjunctively in patients with multiple-seizure types Phich include absence.

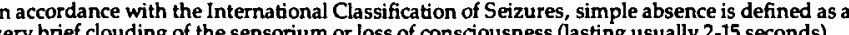
ery brief clouding of the sensorium or loss of consciousness (lasting usually 2-15 seconds) accompanied by certain generalized epileptic discharges without other det
signs. Complex absence is the term used when other signs are also present.

CONTRAINDICATIONS: Depakene (valproic acid) should not be administered to patients with hepatic disease or significant dysfunction; it is contraindicated in patients with known ypersensitivity to the drug.

WARNINGS: Hepatic failure resulting in fatalities has occurred in patients receiving Depakene. These incidences usually have occurred during the first six months of treatment with Depakene. Serious or fatal hepatotoxicity may be preceded by non-specific symptoms such as loss of seizure control, malaise, weakness, lethargy, anorexia and vomiting. Patients and parents should be instructed to report such symptoms. Because of the nonspecific nature
of some of the early signs, hepatotoxicity should be suspected in patients who become unwell, other than through obvious causes while taking sodium valproate. Liver function tests should be performed prior to therapy and at frequent intervals thereafter especially during the first six months. However, physicians should not rely totally on serum biochemistry since these tests may not be abnormal in all instances, but should also conside the results of careful interim medical history and physical examination. Caution should be observed when administering Depakene to patients with a prior history of hepatic disease. Patients with various unusual congenital disorders, those with severe seizure disorders accompanied by mental retardation, and those with organic brain disease may be at

particular risk.

n high-risk patients, it might also be useful to monitor serum fibrinogen and albumin for decrease in concentrations and serum ammonia for increases in concentration. If change occur, valproic acid should be discontinued. Dosage should be titrated to and maintained at the lowest dose consistent with optimal seizure control

The drug should be discontinued immediately in the presence of significant hepatic dysfunctions, suspected or apparent. In some cases, hepatic dysfunction has progressed in spite of discontinuation of drug. The frequency of adverse effects particularly elevated live enzymes may increase with increasing dose. Therefore, the benefit gained by increased seizure control by increasing the dosage must be weighed against the increased incidence of adverse effects sometimes seen at higher dosages.

USE IN PREGNANCY: The safety of Depakene (valproic acid) during pregnancy has not physician should weigh the potential benefits against the possible risks in treating or counselling women of childbearing age who have epilepsy.

Recent reports indicate an association between the use of anticonvulsant drugs and an elevated incidence of birth defects in children born to epileptic women taking such medicatio during pregnancy. The incidence of congenital malformations in the general population is regarded to be approximately $2 \%$; in children of treated epileptic women, this incidence may be increased two to three-fold. The increase is largely due to specific defects, e.g. congenita
malformations of the heart, and cleft lip and/or palate. Nevertheless, the great majonty of mothers receiving anticonvulsant medications deliver normal infants.

Data are more extensive with respect to diphenylhydantoin and phenobarbital, but these drugs are also the most commony prescribed anticonvulsants. Some reports indicate possible similar association with the use of other anticonvulsant drugs, including trimethadione and paramethadione. However, the possibility also exists that other factors, e.g. genetic predisposition or the epileptic condition itself may contribute to or may be mainly responsible for the higher incidence of birth defects.

Anticonvulsant drugs should not be discontinued in patients to whom the drug is administered to prevent major seizures, because of the strong possibility of precipitating Status epilepticus with attendant hypoxia and risks to both the mother and the unborn child. With regard to drugs given for minor seizures, the risks of discontinuing medication prior to
or during pregnancy should be weighed against the risk of congenital defects in the particular case and with the particular family history.

Epileptic women of child-bearing age should be encouraged to seek the counsel of their physician and should report the onset of pregnancy promptly to him. Where the necessity for continued use of antiepileptic medication is in doubt, appropriate consultation might be indicated.

NURSING MOTHERS: Depakene is secreted in breast milk. Concentrations in breast milk have been reported to be 1 to $10 \%$ of serum concentrations. As a general rule, nursing should not be undertaken while a patient is receiving valproic acid.

FER TILITY: Chronic toxicity studies in juvenile and adult rats and dogs demonstrated reduced spermatogenesis and testicular atrophy at doses greater than $200 \mathrm{mg} / \mathrm{kg} / \mathrm{day}$ in rats reduced spermatogenesis and testicular atrophy at doses greater than $200 \mathrm{mg} / \mathrm{kg} /$ day in rats development of the testes and on sperm production and fertility in humans is unknown.

LONG TERM TOXICITY STUDIES IN RATS INDICATED A POTENTIAL

PRECAUTIONS: HEPATIC DYSFUNCTION: SEE CONTRAINDICATIONS AND WARNINGS

GENERAL: Because of reports of thrombocytopenia and platelet aggregation dysfunction, platelet counts and bleeding-time determination are recommended before instituting therap and at periodic intervals. It is recommended that patients receiving Depakene (valproic acid) bruising or a disorder of hemostasis/coagulation is an indication for reduction of Depakene (valproic acid) dosage or withdrawal of therapy pending investigation.

. Hyperammonemia with or without lethargy or coma has been reported and may be present

discontinued.
Because Depakene (valproic acid) may interact with other anticonvulsant drugs, periodic secause Depakene (valproic aod) may interact with other anticonvulsant drugs, periodic
serum leverminatons of such other anticonvulsants are recommended during the early perum level determinatons of Such other anticonvulsants are recommended durng the
seizures occirring with the combination of Depakene and phenytoin. Sepakene (valproic acid) is partially eliminated in the urine as a ketone-containing metabolite
which may lead to a false interpretation of the urine ketone test.

DRIVING AND HAZARDOUS OCCUPATIONS: Valproic acid may produce CNS depression, especially when combined with another CNS depressant, such as alcohol. Therefore, patients should be advised not to engage in hazardous occupations, such as
driving a car or operating dangetous machinery, until it is known that they do not becom driving a car or operating
drowsy from the drug.

DRUG INTERACTIONS: DEPAKENE (VALPROIC ACID) MAY POTENTTATE THE CNS DEPRESSANT ACTION OF ALCOHOL

IHERE IS EVIDENCE THAT VALPROIC ACTD MAY CAUSE AN INCREASE IN SERUM RECEIVING CONCOMITANT BARBITURATE THERAPY SHOULD BE CLOSELY RECEIVING CONCOMITANT BARBITURATE THERAPY SHOULD BE CLOSELY
MONITORED FOR NEUROLOGICAL TOXICTTY SERUM BARBITURATE DRUG LEVELS SHOULD BE OBTAINED, IF POSSIBLE, AND THE BARBITURATE DOSAGE DECREASED IF INDICATED.
Primidone is metabolized into a barbiturate, and therefore, may also be involved in a similar or identical interaction.

THERE IS CONFLICTING EVIDENCE REGARDING THE INTERACTION OF VALPROIC ACID WITH PHENYTOIN. IT IS NOT KNOWN IF THERE IS A CHANGE IN UNBOUND (FREE) PHENYTOIN SERUM LEVELS. THE DOSE OF PHENYTOIN SHOULD BE ADJUSTED AS REQUIRED BY THE CLINICAL SITUATION.

\section{ABSENCE STATUS.}

Caution is recommended when valproic acid is administered with drugs affecting

coagulation, e.g. acetylsalicylic acid and warfarin (see ADVERSE REACTIONS).

ADVERSE REACTIONS: The most commonly reported adverse reactions are nausea, vomiting and indigestion. Since Depakene (valproic acid) has usually been used with other anticonvulsants, it is not possible in most cases to determine whether the adverse reactions mentioned in this section are due to valproic acid alone or to the combination of drugs. GASTROINTESTINAL: Nausea, vomiting and indigestion are the most commonly reported side effects at the initiation of therapy. These effects are usually transient and rarely require discontinuation of therapy. Diarrhea, abdominal cramps and constipation have also been reported. Anorexia with some weight loss and increased appetite with some weight gain have also been seen.

CNS EFFECTS: Sedative effects have been noted in patients receiving valproic acid alone but are found most often in patients on combination therapy. Sedation usually disappears upon reduction of other anticonvulsant medication. A taxia, headache, nystagmus, diplopia, asterixis, "spots before the eyes", tremor, dysarthria, dizziness, and incoordination have rarely been noted. Rare cases of coma have been reported in patients who were also on phenobarbital.

DERMATOLOGIC: Transient increases in hair loss have been observed. Skin rash and petechiae have rarely been noted.

ENDOCRINE: There have been reports of irregular menses and secondary amenorrhea in patients receiving Depakene.

PSYCHLATRIC: Emotional upset, depression, psychosis, aggression, hyperactivity and vioural deterioration have been reported.

MUSCULOSKELETAL: Weakness has been reported.

HEMATOPOIETIC: Thrombocytopenia has been reported. Valproic acid inhibits the second phase of platelet aggregation (see DRUG INTERACIIONS). This may be reflected in altere bleeding time. Bruising, hematoma formation and frank hemorrhage have been reported. Relative lymphocytosis and hypofibrin
eosinophilia have also been reported.

HEPATIC: Minor elevations of transaminases (e.g. SGOT and SGPT) and LDH are frequent and appear to be dose-related. Occasionally, laboratory tests also show increases in serum bilirubin and abnormal changes in other liver function tests. These results may reflect potentially serious hepatotoxicity. (See WARNINGS).

METABOLIC: Hyperammonemia. (See PRECAUTTONS). Hyperglycinemia has been reported and associated with a fatal outcome in a patient with pre-existing nonketotic hyperglycinemia.

PANCREATIC: Isolated reports of pancreatitis in association with valproic acid therapy have

SYMPTOMS AND TREATMENT OF OVERDOSAGE: In a reported case of overdosage with Depakene (valproic acid) after ingesting $36 \mathrm{~g}$ in combination with phenobarbital and phenytoin, the patient presented in deep coma. An EEG recorded diffuse slowing, compatible with the state of consciousness. The patient made an uneventful recovery. Naloxone has been reported to reverse the CNS depressant effects of Depakene overdose. Because naloxone could theoretically also reverse the anticonvulsant effects of Depakene it

As valproic acid is absorbed very rapidly, gastric lavage may be of limited value. General supportive measures should be applied with particular attention

DOSAGE AND ADMINISTRATION: Depakene (valproic acid) is administered orally. The recommended initial dose is $15 \mathrm{mg} / \mathrm{kg} /$ day, increasing at one-week intervals by 5 to 10 $\mathrm{mg} / \mathrm{kg}$ /day until seizures are controlled or side effects preclude further increases. The maximal recommended dose is $60 \mathrm{mg} / \mathrm{kg} /$ day. When the total daily dose exceeds $250 \mathrm{mg}$ it is given in a divided regimen. A 500 -mg enteric coated capsule may be substituted for two 250-mg capsules.

The frequency of adverse effects (particularly elevated liver enzymes) may increase with increasing dose. Therefore, the benefit gained by increased seizure control must be weighed
against the increased incidence of adverse effects.

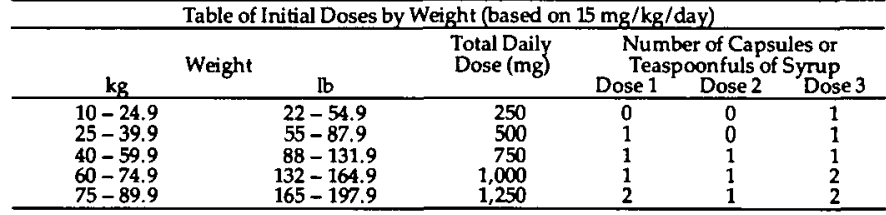

As the dosage of valproic acid is raised, blood levels of phenobarbital and/or phenytoin may be affected (see PRECAUTIONS)

Patients who experience G.I. irritation may benefit from administration of the drug with food or by a progressive increase of the dose from an initial low level. Such patients may benefit chewing to avoid local irritation of the mouth and throat.

AVAILABILITY: Depakene (valproic acid) is available as orange-coloured, soft-gelatin capsules of $250 \mathrm{mg}$ in bottles of 100 capsules (Number 5681 ; DIN 443840); pale yellow, oval soft 507989 ) and as a red syrup containing the equivalent of $250 \mathrm{mg}$ valproic acid, as the sodium
salt, per $5 \mathrm{~mL}$ in bottles of $450 \mathrm{~mL}$ (Number 5682 ; DIN 443832 ).

Depakene is now available in a 500 -mg enteric-coated capsule.

REFERENCES

1. BMJ editorial, March 3, 1979 .

2. Data on file, Abbott Laboratories.

3. Jeavons PM et al: Treatment of generalized epilepsies of childhood and adolescence with sodium valproate. Dev Med Child Neurol 1977; 19: 9-25.

4. Wilder BJ: Valproic acid in clinical use: An overview. Proceedings of the Valproic Acid

5. Coulter DL et al: Valproic acid in childhood epilepsy. JAMA 1980; 244 (8): 785-88. 

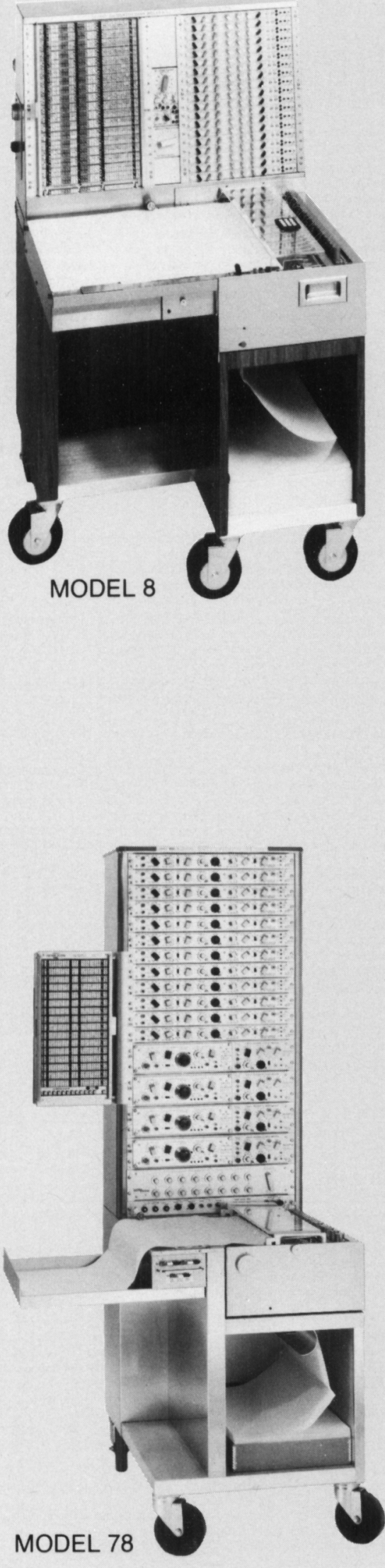

\section{POLYSOMNOGRAPHIC RECORDING FOR CLINIC OR RESEARCH}

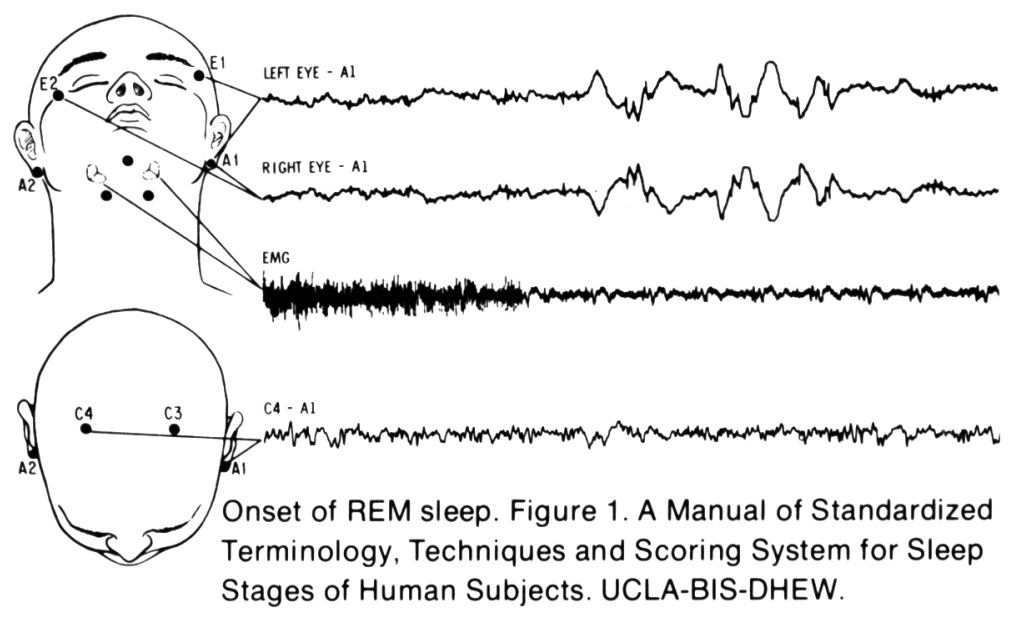

For multiple parameter recording of sleep-wake disorders in the clinical or the research setting, Grass Polygraphs and EEGs have the reliability and flexibility required.

For research applications, the Model 78 Polygraph with a wide selection of interchangeable signal conditioning preamplifiers allows recording several channels of EEG, EOG, EMG, ENG, temperature, respiration, EKG, blood gases, etc., with convenience and ease. A wide range of transducers, recording accessories, plus multiple chart speeds, including the widely used $10 \mathrm{~mm} / \mathrm{sec}$, provide a complete sleep-wake recording system.

For dual purpose applications where the primary interest is in clinical EEG and the secondary interest involves multiple parameter sleep studies, the Model 8 EEG is the instrument of choice.

For dependable long-term studies - rely on Grass, recording bioelectric activity since 1935 .

Write for further information on a system to meet your polysomnographic recording needs.

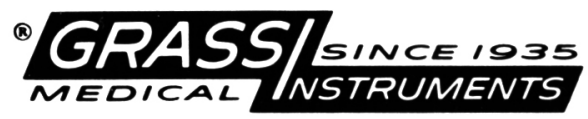

QUINCY, MASS. 02169 • 617/773-0002 